\title{
Characterisation of ground motion recording stations in the Groningen gas field
}

\author{
Rik Noorlandt • Pauline P. Kruiver • Marco P. E. de Kleine • Marios Karaoulis • \\ Ger de Lange • Antonio Di Matteo • Julius von Ketelhodt • Elmer Ruigrok • \\ Benjamin Edwards • Adrian Rodriguez-Marek • Julian J. Bommer • Jan van Elk • \\ Dirk Doornhof
}

Received: 8 June 2017 / Accepted: 14 December 2017 / Published online: 3 January 2018

(C) The Author(s) 2018. This article is an open access publication

\begin{abstract}
The seismic hazard and risk analysis for the onshore Groningen gas field requires information about local soil properties, in particular shear-wave velocity $\left(V_{\mathrm{S}}\right)$. A fieldwork campaign was conducted at 18 surface accelerograph stations of the monitoring network. The subsurface in the region consists of unconsolidated sediments and is heterogeneous in composition and properties. A range of different methods was applied to acquire in situ $V_{\mathrm{S}}$ values to a target depth of at least $30 \mathrm{~m}$. The techniques include seismic cone penetration tests (SCPT) with varying source offsets, multichannel analysis of surface waves (MASW) on Rayleigh waves with different processing approaches, microtremor array, cross-hole tomography and suspension P-S logging. The offset SCPT, cross-hole tomography and common midpoint cross-correlation (CMPcc) processing of
\end{abstract}

R. Noorlandt • P. P. Kruiver $(\varangle) \cdot$ M. P. E. de Kleine

M. Karaoulis - G. de Lange

Deltares, P.O. Box 85467, 3508 AL Utrecht, The Netherlands

e-mail: pauline.kruiver@deltares.nl

\section{A. Di Matteo}

Shell Global Solutions International B.V, Kessler Park 1, 2288

GS Rijswijk, The Netherlands

J. von Ketelhodt

Geotomographie GmbH Germany, now at School of Geosciences, University of the Witwatersrand Johannesburg, WITS 2050, South Africa

\section{E. Ruigrok}

Royal Netherlands Meteorological Institute (KNMI),

Utrechtseweg 297, 3731 GA De Bilt, The Netherlands
MASW data all revealed lateral variations on length scales of several to tens of metres in this geological setting. SCPTs resulted in very detailed $V_{\mathrm{S}}$ profiles with depth, but represent point measurements in a heterogeneous environment. The MASW results represent $V_{\mathrm{S}}$ information on a larger spatial scale and smooth some of the heterogeneity encountered at the sites. The combination of MASW and SCPT proved to be a powerful and cost-effective approach in determining representative $V_{\mathrm{S}}$ profiles at the accelerograph station sites. The measured $V_{\mathrm{S}}$ profiles correspond well with the modelled profiles and they significantly enhance the ground motion model derivation. The similarity between the theoretical transfer function from the $V_{\mathrm{S}}$ profile and the observed amplification from vertical array stations is also excellent.

\section{B. Edwards \\ Department of Earth, Ocean and Ecological Sciences, University of Liverpool, Liverpool L69 3GP, UK}

A. Rodriguez-Marek

Charles E Via, Jr., Department of Civil and Environmental

Engineering, Virginia Tech, Blacksburg, VA 24061, USA

J. J. Bommer

Civil \& Environmental Engineering, Imperial College London,

London SW7 2AZ, UK

J. van Elk • D. Doornhof

Nederlandse Aardolie Maatschappij B.V, Schepersmaat 2, 9405

TA Assen, The Netherlands 
Keywords Shear-wave velocity · Field measurements . MASW - Cross-hole tomography - Seismic cone penetration test $\cdot$ Shallow geology $\cdot$ Lateral heterogeneity

\section{Introduction}

Induced earthquakes due to gas production in the Groningen field in the northern Netherlands has prompted the development of seismic hazard and loss estimation models in order to allow risk-informed decision-making with regard to mitigation options. A key element of the seismic hazard and risk models for the Groningen field is a ground motion prediction model to estimate surface motions due to each possible earthquake scenario. The ground motion model for the Groningen field is comprised of predictive equations for spectral accelerations and peak ground velocity at a reference rock horizon (located at about $800 \mathrm{~m}$ depth) and non-linear frequency-dependent amplification functions reflecting the dynamic response of the overlying soil layers (Bommer et al., 2017).

The ground motion model derivation has benefited from a database of recordings of ground motions obtained from accelerograph and borehole geophone networks installed in the Groningen field. The location of the stations is shown in Fig. 1. The first stage of the model building process is to deconvolve the recorded surface motions to the reference rock horizon. The uncertainty in this process is greatly reduced by the accurate characterisation of dynamic properties of the soil column, particularly in the uppermost tens of metres that exert the strongest influence on the site response. Although an excellent velocity model of the Groningen field has been constructed using measurements at depths from below about $50 \mathrm{~m}$, the near-surface portion of the profiles are inferred from lithological profiles with shear-wave velocities $\left(V_{\mathrm{S}}\right)$ assigned based on available seismic CPT measurements (Kruiver et al., 2017a). To refine the profiles at the locations of the ground motion recording stations, in situ $V_{\mathrm{S}}$ measurements were made using a variety of borehole and non-invasive techniques. Challenges encountered in this work include the fact that in several cases it was not possible to perform the measurements in very close proximity to the location of the recording stations. The paper describes how these tests were conducted and the procedures followed to reconcile the different measurements to construct the final profile for each station.
The measured near-surface profiles also served to demonstrate that the geologically-derived $V_{\mathrm{S}}$ profiles provide a very good approximation to the field conditions. Empirical transfer functions at the recording stations obtained from inversions of the surface recordings (Edwards et al., 2013) agree remarkably well with those calculated using the measured $V_{\mathrm{S}}$ profiles (Bommer et al., 2017). These comparisons not only confirm the reliability of the inferred velocity profiles for the whole field but also vindicate the assumption of $1 \mathrm{D}$ vertical wave propagation implicit in the site response analyses.

No direct $V_{\mathrm{S}}$ measurements have been made at the borehole stations, but interval velocities have been calculated from recordings at these locations and these also show excellent agreement with the inferred profiles for the same locations. The theoretical transfer functions for these profiles, calculated at the surface and $200 \mathrm{~m}$ depth, are similar to the surface-to-borehole spectral ratios of earthquake records.

\section{Methods and setup}

\subsection{Overview}

The shallow subsurface in the Groningen region is of heterogeneous composition as a result of the relatively recent formation. Although site amplification as a result of induced earthquake is present in Groningen to larger depths, the maximum depth of investigation was limited to $30 \mathrm{~m}$. This depth of investigation is not related to $V_{\mathrm{S} 30}$ (time-averaged $V_{\mathrm{S}}$ over the top $30 \mathrm{~m}$ ), but forms a good balance between fieldwork effort and added value of detailed $V_{\mathrm{S}}$ profiles to this depth. The geological setting is described in detail in Kruiver et al. (2017b) and references therein and summarised in this section. The sedimentary infill is influenced by two recent ice ages and by sea level fluctuations. The Elsterian glaciation produced deep subglacial features known as 'tunnel valleys', which were filled with sands and clays of the Peelo Formation. These tunnel valleys were buried by younger sediments. The second glaciation (Drenthe Substage of the Saalian glacial) produced the till sheet that is present in part of the region. The ridge-and-valley topography is still present in the relatively flat landscape. The region was not covered by ice sheets during the last ice-age (Weichselian). During that period, a widespread superficial blanket of eolian sand (the socalled cover sand) that formed in many places marks the 
Fig. 1 Location of recording stations in the Groningen field in the north of the Netherlands: 18 surface stations and 68 vertical array stations. Labels are shown for all 18 surface stations (coded B) characterised in this study and for the vertical array stations (coded $\mathrm{G}$ ) from the examples in this paper (Figs. 16 and 18). Grid coordinates refer to the Dutch Ordnance System. The inset shows the location of the gas field in the northern part of the Netherlands

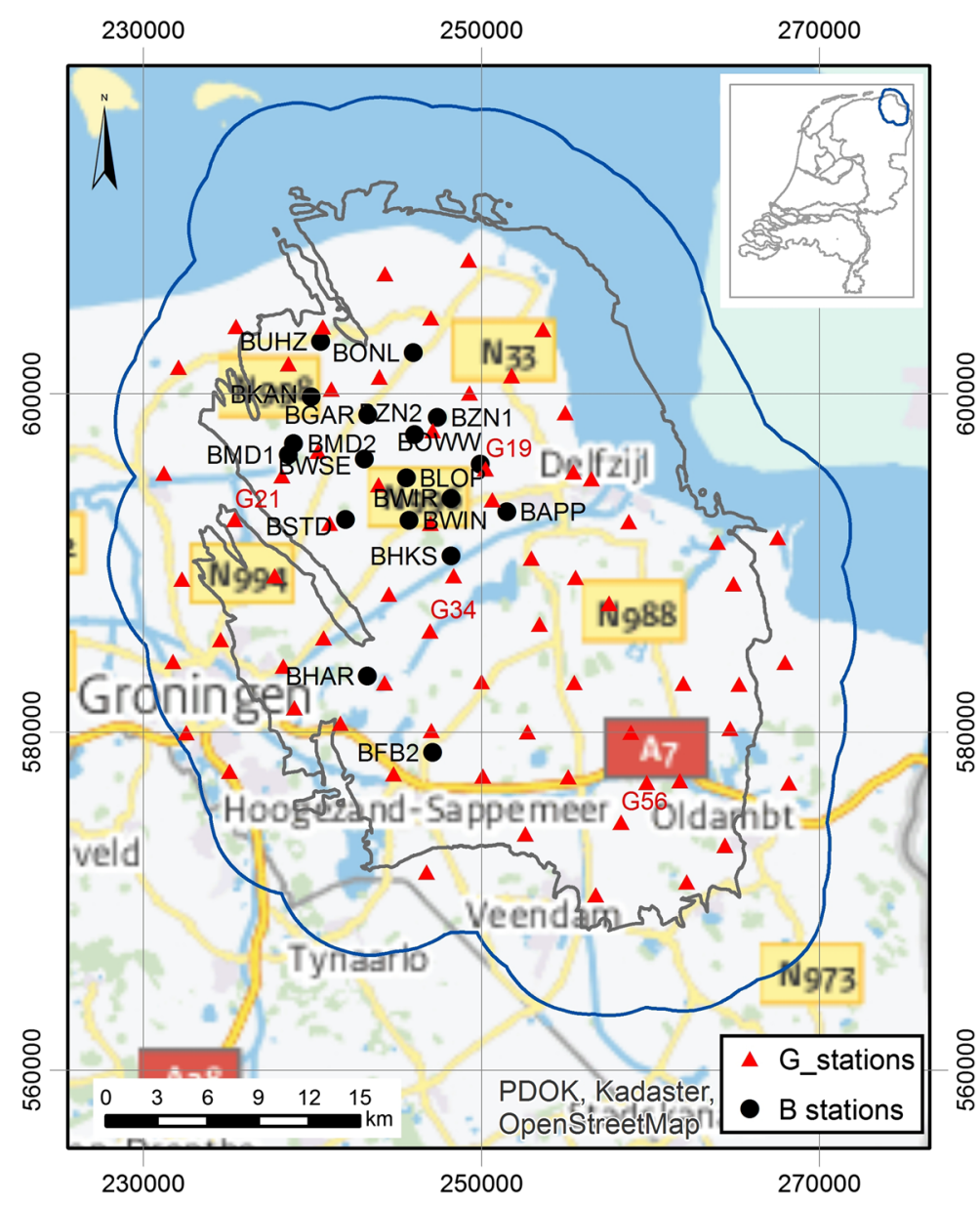

top of the Pleistocene deposits. The northern part of the Netherlands borders the North Sea. During interglacial periods with relatively high sea levels, a large part of Groningen formed the coastal plain of this sea. The most recent Holocene deposits typically consist of stacked vertical sequences of tidal clays and sands that are often thinly bedded and are intermittent with peat layers. The Holocene sediment thickness varies from $\sim 20 \mathrm{~m}$ in the northern part to being absent in the southern part of the region. Due to the presence of various intersection channel systems, namely the Pleistocene tunnel valleys and Holocene tidal channels, the subsurface is very heterogeneous. From the very large number of borings and from the geology, we can infer that infilled channels are present. It is, however, impossible to know the exact location of all individual channels.

In order to characterise the subsoil below the recording stations and considering the level of heterogeneity to be expected, the $V_{\mathrm{S}}$ measurements were to be located as close to the stations as possible. The stations are generally located in barns of farms in the rural areas and in public buildings (e.g. town halls) and houses in villages. Therefore, it was not always possible to locate all measurements in close vicinity of the stations. The distance between the station and the test site varied between 40 and $600 \mathrm{~m}$, with an average distance of $150 \mathrm{~m}$.

Four different $V_{\mathrm{S}}$ techniques were applied at the station locations. This section provides a short description of acquisition and processing for each of the methods. The survey setup is summarised in Table 1 . Although the methods are routinely used in site characterisations (e.g. Garofalo et al. 2016a, b), we have implemented several adjustments to either improve the acquisition or the processing and interpretation of results. Suspension P-S logging (Ohya et al., 1984; Ogura et al., 1989) was applied unsuccessfully during this survey campaign, probably due to the combination of the borehole construction, grouting and the local geological setting. Therefore, these data were not further processed and interpreted. 


\subsection{SCPT}

Seismic cone penetration tests consist of a normal CPT with a geophone or accelerometer contained in the cone. The cone is penetrated into the soils and stopped at defined depth intervals for a $V_{\mathrm{S}}$ measurement. Shear waves were generated at the surface by striking a 10 $\mathrm{kg}$ sledgehammer on opposite sides of $2.5 \mathrm{~m}$ hardwood beams. Typically, the cone penetration is stopped every $1.0 \mathrm{~m}$ and the source is located $\sim 1 \mathrm{~m}$ from the entry point at the surface (Butcher et al., 2005). In the Groningen case, alternations between peat, clay and sand occur at irregular intervals that are often smaller than $50 \mathrm{~cm}$. In order to correctly sample the $V_{\mathrm{S}}$ of for each individual stratigraphy, the depth intervals at which the cone was stopped were determined by a normal CPT that preceded the SCPT. For example, when an $80-\mathrm{cm}$ thick peat layer was present between 1.7 and $2.5 \mathrm{~m}$ on top on of sand, a $V_{\mathrm{S}}$ measurement was performed at 1.7 and $2.5 \mathrm{~m}$ instead of at 2.0 and $3.0 \mathrm{~m}$. In this way, the peat $V_{\mathrm{S}}$ was not contaminated by the much stiffer sand below it. Sources at offsets of 5, 10, 15 and $20 \mathrm{~m}$ were added to the standard $1.1 \mathrm{~m}$ source to gain insight in short-spaced lateral variations in $V_{\mathrm{S}}$ (Fig. 2). This is referred to as offset SCPT (OSCPT). Coupling of the wooden beams to the ground was increased by sand bags. At each source location, three shots were performed and stacked at each depth, both from the left and right sides of the beam. The maximum target depth of SCPTs was $30 \mathrm{~m}$, but in some cases the measurement was terminated earlier (e.g. at $\sim 20 \mathrm{~m}$ ) when the cone could not be penetrated further upon reaching the maximum capacity of the truck.

SCPT data were processed using the BCE SC3-RAV 2015 seismic data analysis software (Version 15.0.1June 2015). This software allows semi-automatic interval time picking using cross-correlation of the wave trains of subsequent test depths. The algorithm uses a simple ray tracing principle based on a horizontal stratigraphy model to determine the travel path length to calculate the interval shear-wave velocities. The left and right shots from the shear-wave source were processed separately. The traces for the OSCPT had to be handpicked due to the lower signal-to-noise ratio for the larger offsets. The model subsurface from the OSCPT data was discretised using a grid of nodes, with a node distance of $0.5 \mathrm{~m}$. For each of the nodes, the optimum $V_{\mathrm{S}}$ was determined by minimising the misfit defined as the root-mean-square (RMS) between the modelled travel times and the measured travel times. The 'fast marching method' (Sethian, 1999) was used to calculate the modelled travel times of seismic waves from source to receivers. For the optimisation, the Fresnel ray-path approach (Watanabe et al., 1999) was used. An example of CPT soundings and SCPT $V_{\mathrm{S}}$ profiles for station BLOP is given in Fig. 3. The distance between the (S)CPTs is $\sim 80 \mathrm{~m}$. The CPT soundings show transitions at 8-9 $\mathrm{m}$ (Naaldwijk clay to Boxtel sand and DrenteGieten clayey sand), 11.5-12 m (Drente-Gieten clayey sand to Peelo fine sand) and 15.5-16.5 m (Peelo fine sand to Peelo medium sand). The transitions in two nearby (S)CPTs do not occur at the exactly same depth, illustrating the heterogeneity of the geology. The transition between Holocene and Pleistocene Formations at 8-9 m depth can be clearly observed as a jump in the SCPT $V_{\mathrm{S}}$ profiles. The effect of the transition between different lithoclasses within the Peelo Formation at 15$16 \mathrm{~m}$ depth is rather subtle. The OCPTs images (Fig. 4) are much smoother than an individual SCPT $V_{\mathrm{S}}$ profile. Figure 4 consistently shows the Holocene/Pleistocene $V_{\mathrm{S}}$ transition and the Boxtel/Drente-Gieten Formations on top of the Peelo Formation. The Boxtel Formation can be cemented very locally, giving rise to relatively high $V_{\mathrm{S}}$ values. The OSCPT images show that even on very short $\left(\sim\right.$ metre) spatial scales the values of $V_{\mathrm{S}}$ and the transition depths vary.

\subsection{MASW and microtremor array method}

The MASW method uses the dispersive behaviour of surface waves, i.e. the fact that the different frequencies of the wave signal travel with different speeds, to derive $V_{\mathrm{S}}$ profiles with depth (Park et al. 1999). The dispersion of a wave can be determined using multiple receivers that record the passage of a surface wave. The surface wave itself can be actively generated for the analysis, for example with a hammer blow or weight drop, or can be of ambient origin, like traffic or ocean noise. If active source and ambient noise recordings contain different frequency ranges, they might be combined to increase the depth range and resolution. However, while the prominent source direction is known in an active acquisition, in ambient noise acquisition it is unknown beforehand. Therefore, we acquired the seismic data using T-shaped arrays, with different sets of geophones, as visualised in Fig. 5 and summarised in Table 1. The main line consisted of $964.5-\mathrm{Hz}$ geophones (72 in the first locations). To obtain lower frequency content 121 - 
Table 1 Summary of survey setup for the four different shear-wave methods

\begin{tabular}{|c|c|c|c|c|c|}
\hline & SCPT & MASW & $\begin{array}{l}\text { Microtremor } \\
\text { array }\end{array}$ & $\begin{array}{l}\text { Cross-hole } \\
\text { tomography }\end{array}$ & $\begin{array}{l}\text { Suspension P-S } \\
\text { logging }\end{array}$ \\
\hline Source & $\begin{array}{l}\text { Wooden beam and } \\
\text { sledgehammer at } \\
1.1,5,10,15 \text { and } \\
20 \mathrm{~m} \text { from SCPT } \\
\text { truck }\end{array}$ & $\begin{array}{l}\text { Accelerated weight } \\
\text { drop 'Impacter' }\end{array}$ & $\begin{array}{c}\text { Ambient } \\
\text { noise }\end{array}$ & Borehole source of type BIS-SH & $\begin{array}{l}\text { Hammer source in } \\
\text { tool }\end{array}$ \\
\hline Receivers & $\begin{array}{l}\text { 3-component } \\
\text { accelerometer in } \\
\text { SCPT cone }\end{array}$ & $\begin{array}{l}96 \text { to } 120 \text { planted } \\
\text { vertical } 4.5 \mathrm{~Hz} \\
\text { geophones } \\
12 \text { planted vertical } \\
1 \mathrm{~Hz} \text { geophones }\end{array}$ & $\begin{array}{l}\text { Planted } \\
\text { geophones } \\
\text { of MASW } \\
\text { array }\end{array}$ & $\begin{array}{l}\text { 3-component geophone string of } \\
7 \text { units with spacing of } 1.0 \mathrm{~m}\end{array}$ & $\begin{array}{l}\text { Two 3-component } \\
\text { hydrophone re- } \\
\text { ceivers in tool sep- } \\
\text { arated by acoustic } \\
\text { damping tubes }\end{array}$ \\
\hline Remark & $\begin{array}{l}\text { Vertical sample } \\
\text { interval max } \\
1.0 \mathrm{~m} \text { and } \\
\text { coinciding with } \\
\text { stratigraphical } \\
\text { transitions }\end{array}$ & $\begin{array}{l}\text { T-shaped array with } \\
\text { geophone spacing } \\
\text { of } 2.0 \text { or } 3.0 \mathrm{~m} \\
(4.5 \mathrm{~Hz}) \text { and } \\
4.0 \mathrm{~m}(1 \mathrm{~Hz}) .\end{array}$ & $\begin{array}{l}\text { Recording of } \\
70-80 \times 3- \\
2 \mathrm{~s} \\
(120 \times 1- \\
6 \mathrm{~s} \text { at one } \\
\text { site })\end{array}$ & $\begin{array}{l}\text { L-shaped array of } 3 \text { boreholes with } \\
\text { the source the corner of the } \mathrm{L} \text { and } \\
\text { the receivers in borehole at } 10 \\
\text { (short leg of L) or } 25 \mathrm{~m}(\log \text { leg } \\
\text { of } \mathrm{L}) \text {. Boreholes are lined with } \\
\text { blind liners }\end{array}$ & $\begin{array}{l}\text { In one of the } \\
\text { boreholes for } \\
\text { cross-hole tomog- } \\
\text { raphy }\end{array}$ \\
\hline $\begin{array}{l}\text { Depth of } \\
\text { investigation }\end{array}$ & $20-30 \mathrm{~m}$ & $15-50 \mathrm{~m}$ & $10-50 \mathrm{~m}$ & $30 \mathrm{~m}$ & $30 \mathrm{~m}$ \\
\hline $\begin{array}{l}\text { Lateral } \\
\quad \text { averaging }\end{array}$ & $\sim 2 \mathrm{~m}$ & Up to $\sim 200 \mathrm{~m}$ & & $\sim 1 \mathrm{~m}$ & $\sim 1 \mathrm{~m}$ \\
\hline $\begin{array}{l}\text { Vertical } \\
\text { resolution }\end{array}$ & $\begin{array}{l}\text { High, except } \\
\text { shallow part }\end{array}$ & $\begin{array}{l}\text { Medium, } \\
\text { decreasing with } \\
\text { depth }\end{array}$ & $\begin{array}{l}\text { Medium, } \\
\text { decreasing } \\
\text { with depth }\end{array}$ & High & High \\
\hline
\end{tabular}

$\mathrm{Hz}$ geophones were placed parallel to the main line. Perpendicular to the main line 24 4.5- $\mathrm{Hz}$ geophones were placed for directionality analysis. For the active data acquisition an accelerated weight drop source ('Impacter') was used, at the shot locations indicated in Fig. 5.

Our analysis of MASW and microtremor array data is based on records of Rayleigh waves. Generally, the lowest frequency of both microtremor array and MASW data is 2 to $4 \mathrm{~Hz}$ and the maximum usable wavelength under the assumption of a homogeneous medium ranges

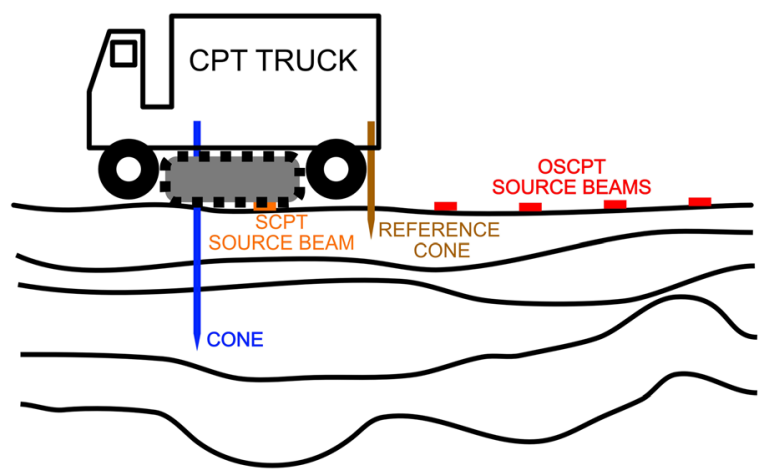

Fig. 2 Schematic illustration of offset SCPT setup (not to scale) between $\sim 40$ and $200 \mathrm{~m}$. Given the heterogeneous and layered subsurface of the Groningen region, with low $V_{\mathrm{S}}$ layers and $V_{\mathrm{S}}$ values decreasing at certain depths, the theoretical wavelength at a certain frequency does not represent the true penetration depth. Although wavelengths of about $200 \mathrm{~m}$ were observed, the inversion of the data showed that typical penetration depth was in the order of 10 to $50 \mathrm{~m}$.

The dispersion analysis of the MASW data was done in two ways, making use of the different source locations. The first method focuses on getting the highest resolution dispersion plot for the whole line, while the second method focuses on determining multiple (lower resolution) dispersion plots along the array to detect heterogeneity within the array. The basic idea behind the methods is sketched in Fig. 6. The static array was used in two ways to combine multiple shot locations. In the method sketched in the top row, the geophones are sorted on source-receiver offset to get a densely-sampled virtual record. This is referred to as an offset gather. For the main line the sampling was improved from 96 channels at $2 \mathrm{~m}$ interval to 192 channels at $1 \mathrm{~m}$ interval by shifting the source by $1 \mathrm{~m}$. In this way, the spatial sampling interval is halved and the amount of data is 

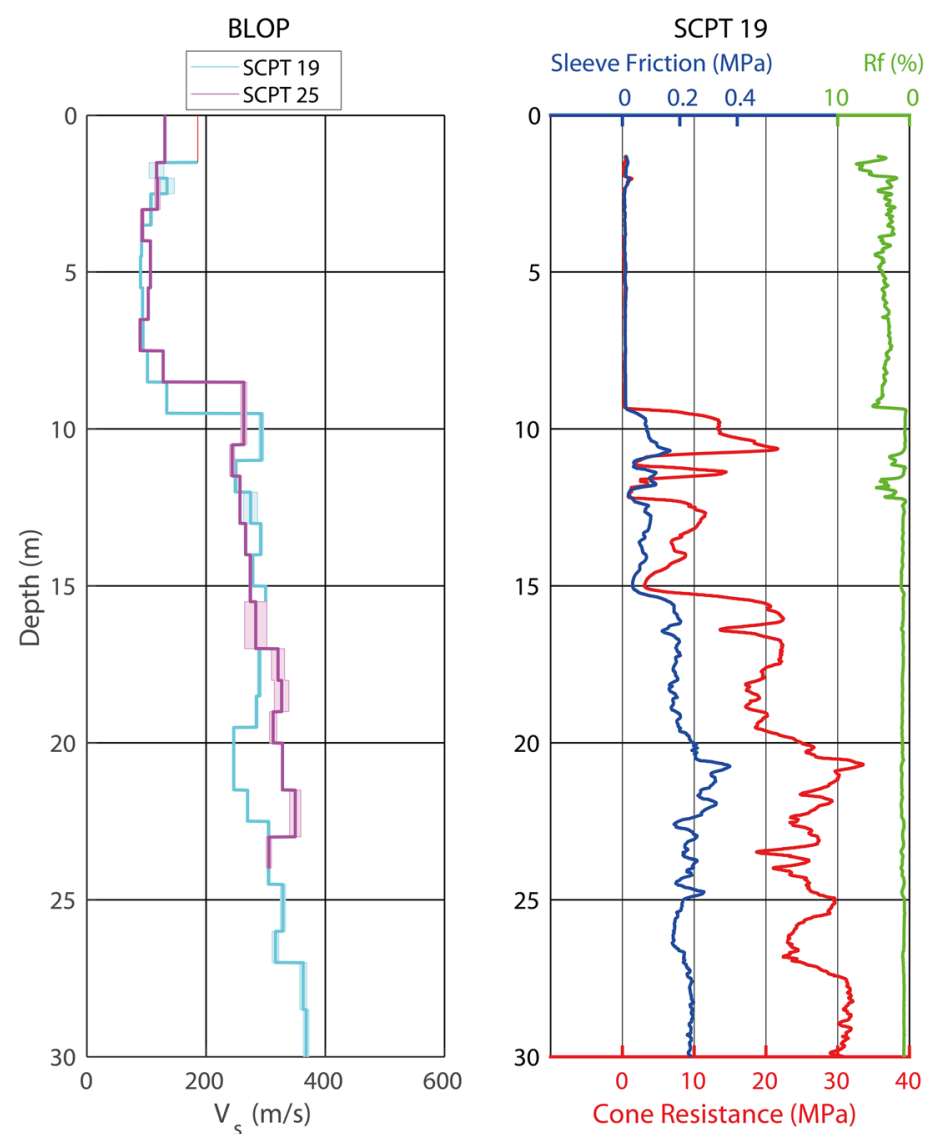

SCPT 25

Sleeve Friction (MPa) $\quad \operatorname{Rf}(\%)$

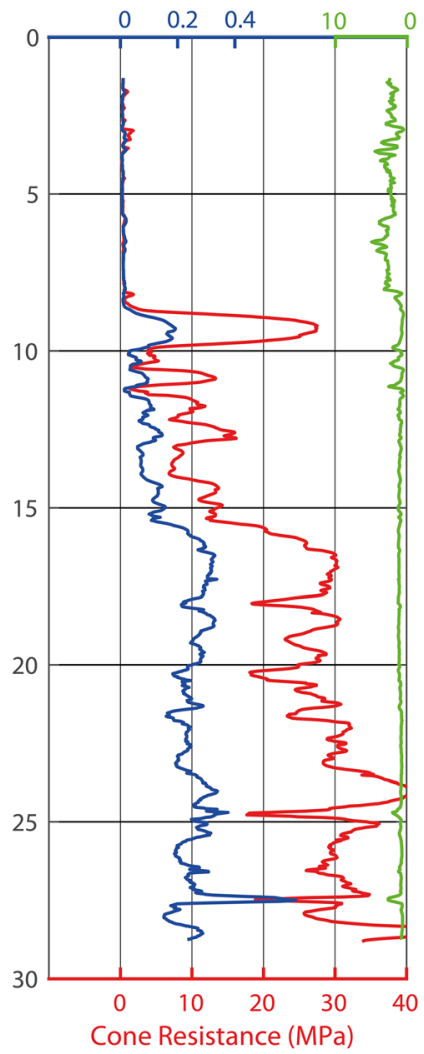

Fig. 3 CPT and SCPT data for station BLOP. Left: $V_{\mathrm{S}}$ profiles of SCPT 19 (blue) and SCPT 25 (purple). The shaded band indicates the results from the left and the right blow. Middle and right: CPT

soundings of SCPT 19 and SCPT 25, with cone resistance in red, sleeve friction in dark blue and friction ratio $\mathrm{Rf}$ in green
Fig. 4 OSCPT result for SCPT19 (left) and SCPT25 (right) for station BLOP

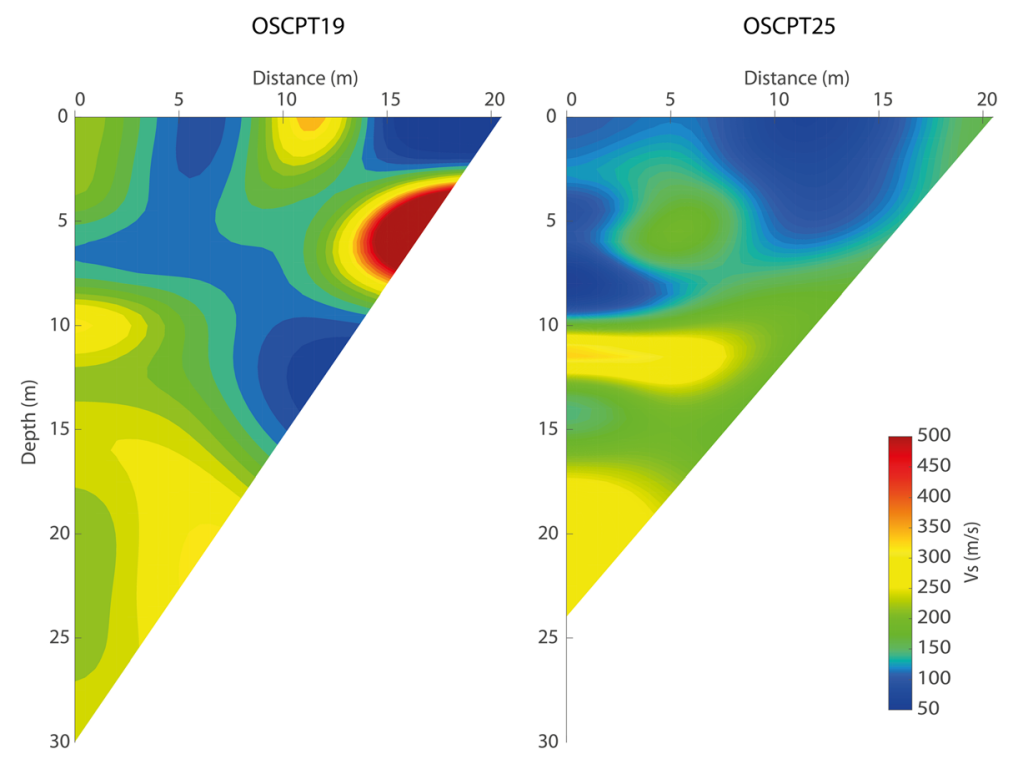


doubled. This procedure was possible because the Impacter (accelerated weight drop) produced a repeatable signal.

The second method focuses on determining heterogeneity and is sketched in the bottom row of Fig. 6 . The influence of the source-receiver offset is removed by correlating the recordings from different receivers, for subsequent sources, and stacking these correlations over the sources. Virtual records along the array are generated using different correlation pairs. The dispersion behaviour of the virtual records is determined using the common midpoint cross-correlation approach (CMPcc) approach (Hayashi and Suzuki, 2004). Although 96 geophones can be combined to form a maximum of 4560 correlation pairs, approximately one third of the combinations were used. This is to ensure equal numbers of pairs in each CMPcc bin (Fig. 7). For visualisation purposes, the array has been reduced to 24 geophones in this figure, but the same principle applies to the 96 geophones of our array. Correlations are binned based on the midpoint of the geophone pairs being correlated. The different offsets between the correlation pairs within a bin are used to determine the dispersion for each bin. A minimum number of correlation pairs within a bin is required to estimate the dispersion with sufficient confidence. Therefore, the first and last bins cannot be used for dispersion plotting because they contain an insufficient number of pairs spanning too limited an offset. This applies to the first two and last three bins in Fig. 7. Correlations pairs with too large an offset were excluded as well, because the purpose of the CMPcc analysis was to investigate heterogeneity. This procedure ensures that each bin contains the same number of correlation pairs. Therefore, changes in dispersion can be attributed to differences of ground properties, rather than to resolution differences between the bins. Our CMPcc bins contained 24 geophone pairs per bin, spanning an offset between 2 and $48 \mathrm{~m}$. Dispersion plots were generated from the CMPcc bins for waves that were travelling from 'left-to-right' as well as for 'right-to-left' travelling waves. The best quality dispersion plot was selected for analysis.

The dispersion plots found by the classic MASW and the CMPcc approach were inverted to derive $V_{\mathrm{S}}$ models and investigate the $V_{\mathrm{S}}$ variation along the profile. The inversion algorithm searches the model space to find the $V_{\mathrm{S}}$ profile with the minimum misfit between the modelled dispersion curve and the measured energy on the dispersion plot. The most likely $V_{\mathrm{S}}$ model for each data set was determined with in-house software by manual optimisation and by applying an automated genetic algorithm. The full array was processed both manually and automatically. The CPMcc gathers were processed automatically. For the manual optimisation, the SCPT $\mathrm{V}_{\mathrm{S}}$ model was used as a starting model. The emphasis of this exercise was to obtain the $V_{\mathrm{S}}$ model that fits all modes and the particular shapes of the modes, such as curvatures at certain frequencies. The genetic algorithm automatically generates numerous $V_{\mathrm{S}}$ model realisations, each associated with a modelled dispersion curve. The best $V_{\mathrm{S}}$ model from the manual optimisation was used to define the search space of the automatic algorithm. The goodness of fit was defined by the energy of the dispersion plot along the modelled dispersion curve. After a number of iterations, the genetic algorithm converges to a group of likely models. The best $V_{\mathrm{S}}$ model is chosen from this group based on the best goodness of fit. Figure 8 shows an example of a dispersion plot of the full line array of 96 geophones and resulting $V_{\mathrm{S}}$ profiles obtained with the two inversion approaches. Generally, the two approaches result in the same pattern of $V_{\mathrm{S}}$, but the transition depths and $V_{\mathrm{S}}$ values of the individual layers vary between the methods. The theoretical fundamental and the higher modes corresponding to the $V_{\mathrm{S}}$ profile for both methods are shown in the dispersion plot. Only the fundamental mode is used in the goodness of fit definition in the genetic algorithm. All modes are considered in the visual inspection of the fit between the model and the data in the manual approach. The maximum depth of reliable $V_{\mathrm{S}}$ information was determined by a sensitivity analysis of the deeper layers to changes in depth and $V_{\mathrm{S}}$ during the manual procedure. The maximum reliable depth for $V_{\mathrm{S}}$ varied between $10 \mathrm{~m}$ for a site with a very thick layer of low $V_{\mathrm{S}}$ to $\sim 50 \mathrm{~m}$ for sites with stiffer soils.

The CMPcc result for station BWIR is shown in Fig. 9. The top left panel shows the best $V_{\mathrm{S}}$ model for each of the 72 CMPcc gathers as determined using the genetic algorithm. The $V_{\mathrm{S}}$ profile resulting from each CMPcc gather is represented by a colour-coded column. The panel of 72 columns does not represent a 2D $V_{\mathrm{S}}$ profile, because of the large overlap in data between in the CMPcc models (Fig. 7). However, the plot is indicative of variation in thickness and $V_{\mathrm{S}}$ values of the individual layers along the full array of $\sim 200 \mathrm{~m}$ length. The transition between Holocene and Pleistocene deposits at $\sim 8-9 \mathrm{~m}$ (in SCPT) varies between $\sim 4$ and $9 \mathrm{~m}$. The bottom left panel of Fig. 9 shows the standard 
Fig. 5 Survey setup for MASW and microtremor array with planted geophones. Triangles represent geophone locations, and stars represent shot locations

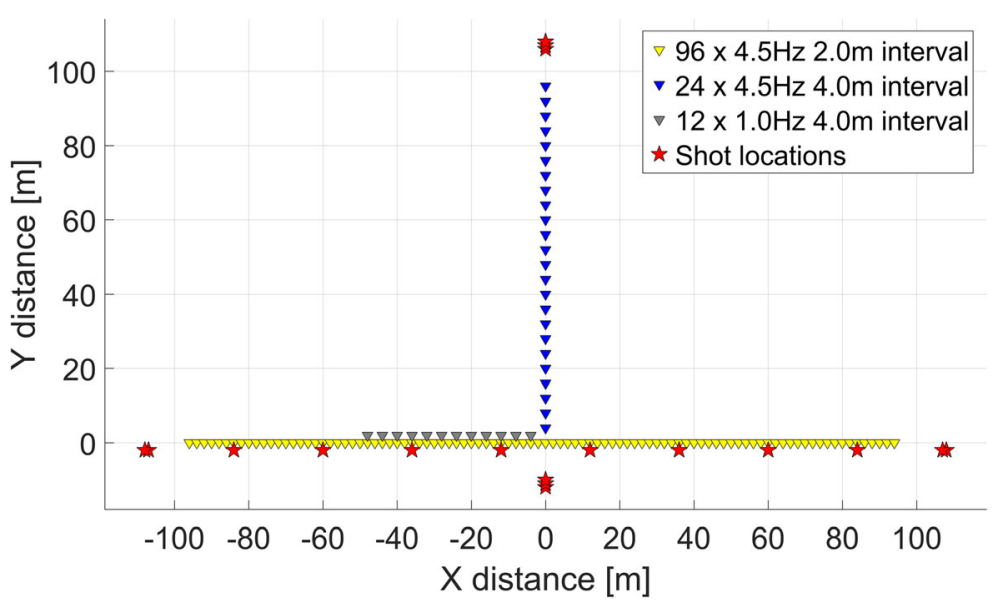

deviation of the group of best models for each CMPcc gather. The standard deviation varies laterally as well and is generally higher for deeper layers. This means that $V_{\mathrm{S}}$ for deeper layers is less well constrained. The aggregated results of the CMPcc analysis are shown in the right panel of Fig. 9. The transitions between the model layers appear to be smeared relative to the standard MASW interpretation which shows sharp transitions (Fig. 8).

Passive or ambient-vibration-based surface wave methods record background vibrations emanating from ocean wave activity, atmospheric conditions, wind effects, traffic, industrial, construction activities, etc., which collectively are referred to as microseisms. Examples of application of microseism techniques can be found in Yong et al. (2013). Typically, microseisms with frequencies below $1 \mathrm{~Hz}$ have natural origins, whereas those above $1 \mathrm{~Hz}$ are largely due to human activities (Okada, 2003). As frequencies below $1 \mathrm{~Hz}$ are difficult to generate by active sources, microseisms can help increasing the bandwidth at the low end and therefore the microtremor array technique will usually extend the depth of investigation of MASW.

The microtremor array experiment was conducted to test whether the MASW data could be enhanced by
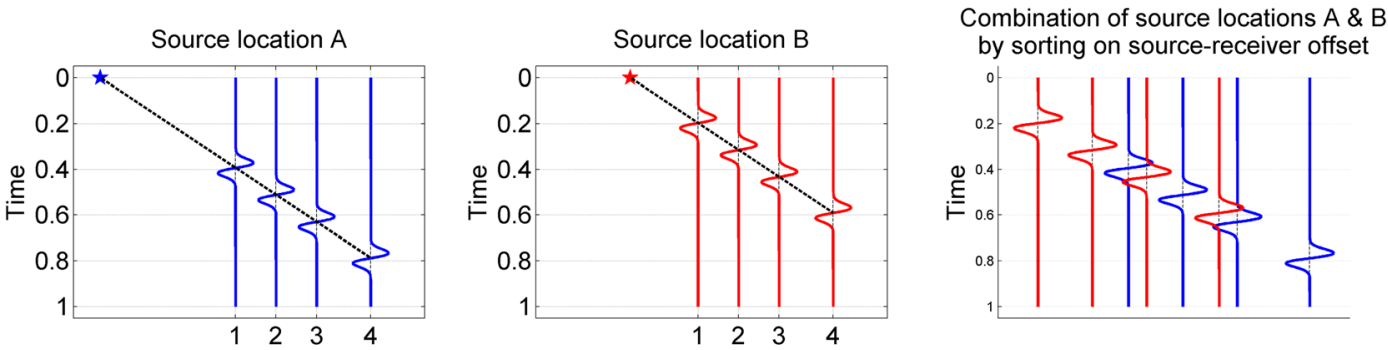

After correlation with first geophone
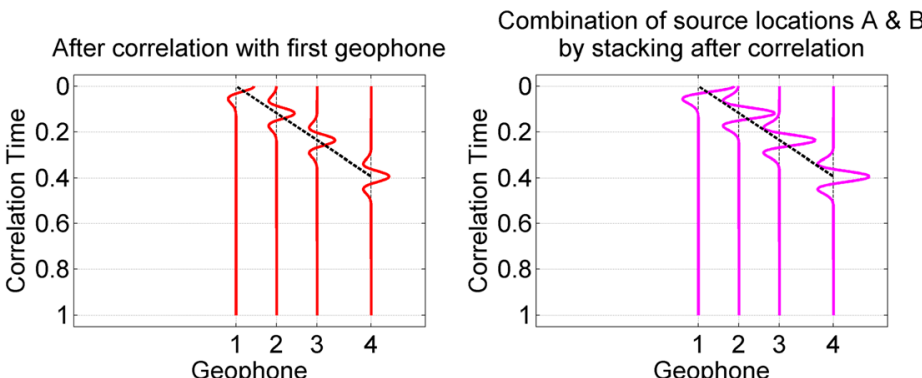

Fig. 6 Sorting and pre-processing of MASW data to obtain offset gathers (top) and geophone correlation gathers (bottom) to prepare for CMPcc binning 
Fig. 7 Schematic representation of CMPcc binning. Geophones are represented by yellow triangles, and the correlation midpoints are indicated by dots. The correlations within the grey zone are used for analysis. Only bins with a sufficient number of midpoints are used (bins 3 to 20 in this example) and fixed offset range (6 geophones in this example)

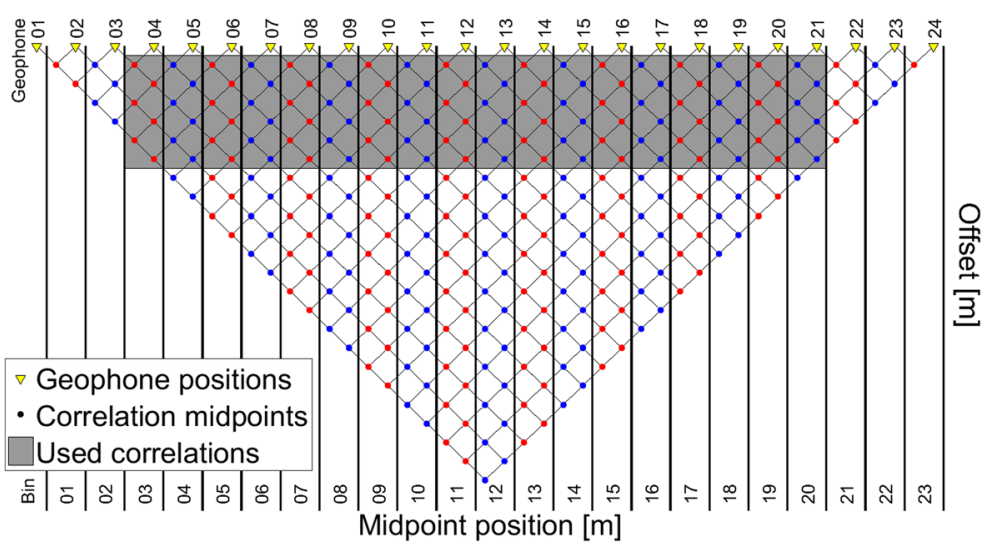

including ambient noise data. The microtremor array data were acquired using the same planted geophone arrays as the MASW with a source (Table 1). However, this time ambient noise was recorded. At each site, between 70 and 80 recordings were made, each with duration of $32 \mathrm{~s}$ at a sample interval of $2 \mathrm{~ms}$. The microtremor array data were processed using the extended spatial autocorrelation (ESAC) technique (e.g. Mulargia and Castellaro, 2013). ESAC is based on the spatial autocorrelation (SPAC) method of Aki (1957). A drawback of the ESAC method is that only a single dispersion curve is determined, most likely the fundamental mode, but the method is considered more suitable for microtremor array measurements than frequency-wavenumber spectrum (fk) methods (Ohori et al., 2002). Figure 10 shows the dispersion information obtained from the microtremor array and active source data acquired at station BGAR. The dispersion curve from the microtremor array measurements (red dots in Fig. 10) agrees well with the fundamental mode in the dispersion plot of the MASW data (greyscale dispersion plot of Fig. 10). However, the microtremor array data do not significantly extend the bandwidth of the dispersion data.

During the processing of the microtremor array dataset, it was not possible to extract surface wave dispersion data from the ambient noise acquired at sites BAPP and BHKS. The MASW results indicate the presence of a thin, low-velocity $\left(V_{\mathrm{S}} \sim 50 \mathrm{~m} / \mathrm{s}\right)$ surface layer at these sites. Lateral variations in thickness and $V_{\mathrm{S}}$ of top layers have a relatively large influence on the dispersion in the EPAC procedure and can affect the whole $V_{\mathrm{S}}$ model. The dispersion energy in the dispersion plot therefore becomes less reliable or impossible to define on the dispersion curve. The MASW data for these two stations showed good quality dispersion plots. The maximum resolved depth of stations BAPP and BHKS was limited to $\sim 10-20 \mathrm{~m}$ (instead of $30 \mathrm{~m}$ ) due to the presence of the very low-velocity layer at the top.
Fig. 8 MASW result for station BWIR. Left: $V_{\mathrm{S}}$ profiles from the manual optimisation (solid line) and the genetic algorithm (dashed line). Right: dispersion plot showing the energy in the velocityfrequency domain in grey scale and the theoretical dispersion curves for the $V_{\mathrm{S}}$ profiles of the left panel for the manual optimisation (solid line) and the genetic algorithm (dashed line). The fundamental mode is shown in green; the higher modes in red, blue, cyan and yellow
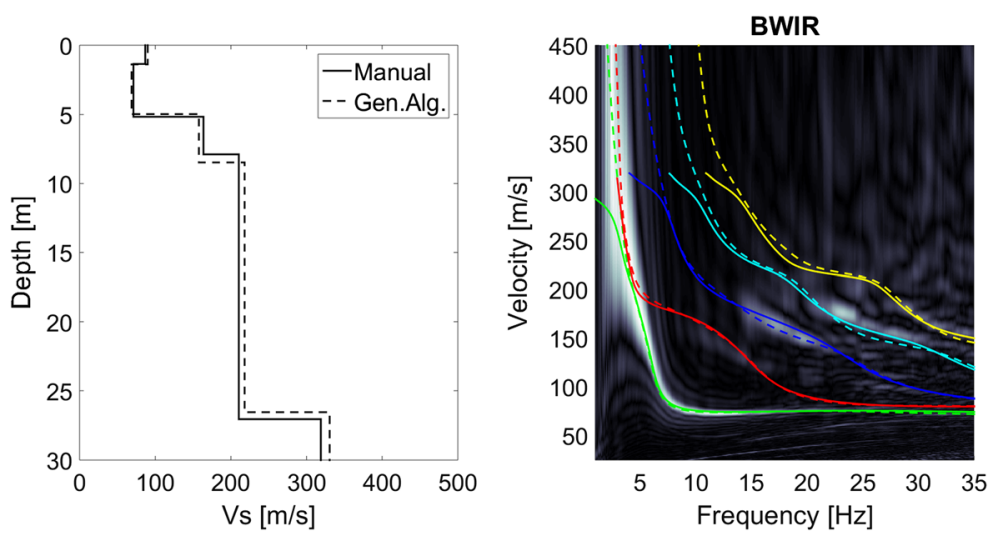

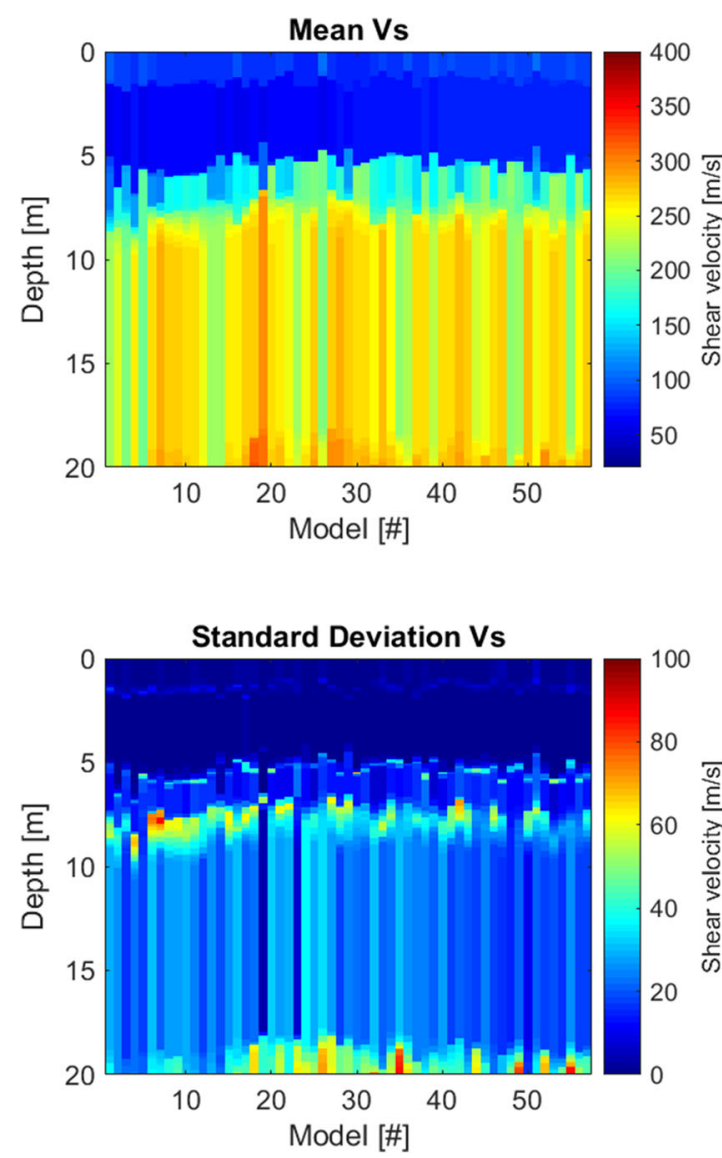

Fig. 9 CMPcc result for station BWIR. Top left: mean of best $V_{\mathrm{S}}$ models for the $72 \mathrm{CMPcc}$ gathers along the line. Bottom left: standard deviation of best $V_{\mathrm{S}}$ models for the $72 \mathrm{CMPcc}$ gathers

Another means to extend the low-frequency range of the MASW is to use low-frequency geophones. We installed $1 \mathrm{~Hz}$ geophones which partially coincided with the $4.5 \mathrm{~Hz}$ array (Fig. 5). Because of the high costs of these geophones, only 12 were available, which creates a very short array. Nonetheless, the dispersion plots of the $1 \mathrm{~Hz}$ array and the $4.5 \mathrm{~Hz}$ array are compared in Fig. 11. The effect from the number of geophones in the array is clear from the top and middle panel, both for the $4.5 \mathrm{~Hz}$ geophones. Reduction of the number of geophones results in smeared dispersion energy. The $1 \mathrm{~Hz}$ array shows more lowfrequency energy than the corresponding $4.5 \mathrm{~Hz}$ array (bottom versus middle panel). In the current setup, however, the quality is insufficient to be able to extend the dispersion curve to lower frequencies. The quality could be improved by using a low-frequency source such as a low-frequency shear wave vibrator and by deploying more $1 \mathrm{~Hz}$ geophones at larger
BWIR

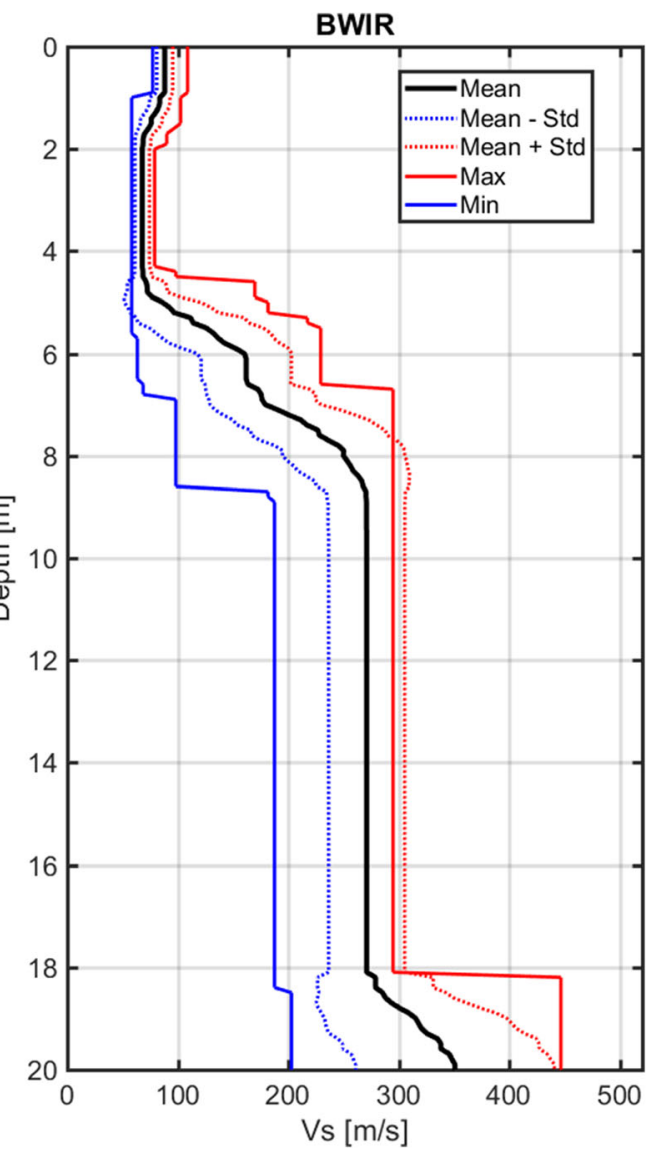

along the line. Right: best fit curve of the 72 models with the maximum and minimum value observed in the whole CMPcc and the standard deviation from all models

distances between the geophones. Ambient noise recording using the extended $1 \mathrm{~Hz}$ array might also increase the low energy content of the dispersion plot.

\subsection{Cross-hole tomography}

The cross-hole tomography data were acquired using three boreholes in an L-shaped configuration. The shear wave source was located in the corner of the $\mathrm{L}$, while the receiver string was located either at $10 \mathrm{~m}$ at the end of the short leg of the $L$ or at 25-26 $\mathrm{m}$ at the end of the long leg of the L. Thus, the shots were performed twice: once recorded by the receiver array in the borehole of the short leg and once recorded by the receiver array in the borehole of the long leg. This geometry was chosen to generate tomographic images at two different scales and in two directions. The borehole source is coupled to the borehole wall by a pneumatic clamping system (inflatable bladder). The 
Fig. 10 Dispersion curves determined with the ESAC method applied on the passive data at BGAR (red dots) plotted on top of the (black and white) dispersion plot determined for the active data using the MASW method

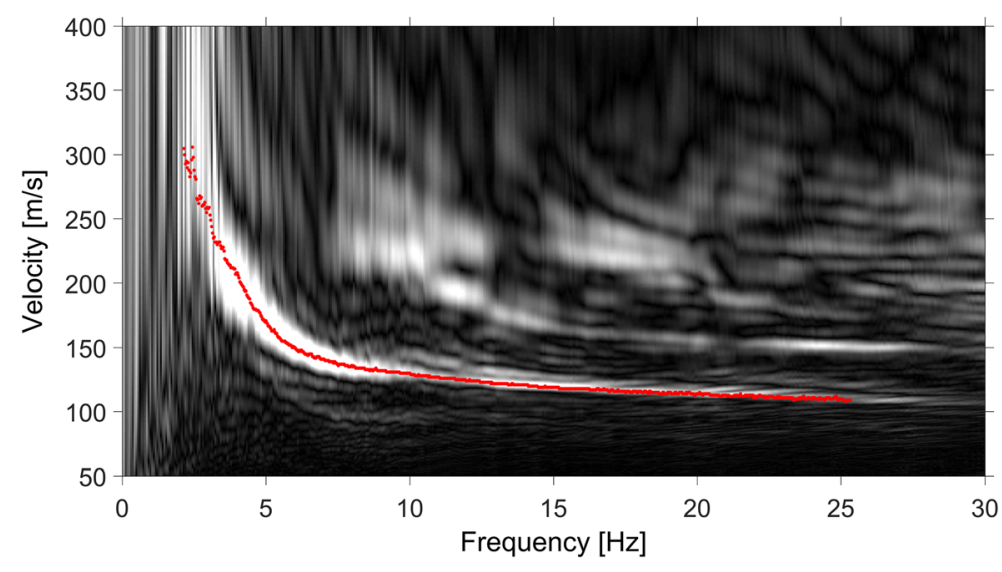

orientation of the source is controlled from the surface by a torsional stiff hose. The seismic blow direction was aligned perpendicular to the receiver borehole in order to generate $\mathrm{SH}$-waves. To obtain the opposite blow direction the source was rotated by $180^{\circ}$, thus generating $\mathrm{S}$ waves with opposite polarities. For each shot direction a separate seismic record was acquired. The source also generated $\mathrm{P}$ waves.

The cross-hole seismic data processing included several steps. First, the travel times were determined manually by picking the arrivals of both the $\mathrm{P}$ and $\mathrm{S}$ waves. Next, the subsurface was numerically divided into cells. Vertical and horizontal cell sizes of approximately $1 \mathrm{~m}$ were selected. Seismic waves are assumed to propagate along curved ray paths. The simultaneous iterative reconstructive technique (SIRT; Gilbert, 1972) algorithm was used for travel time inversion. This algorithm is iterative and minimises the residual of the observed and calculated seismic travel times by a correction of the seismic slowness, i.e. the reciprocal of the seismic velocity in each cell. The tomograms for each borehole set were processed separately. An example of a $V_{\mathrm{S}}$ and a $V_{\mathrm{P}}$ tomogram is shown in Fig. 12. The heterogeneity of the sediment at short distance scales is apparent. The transition from relatively low $(\sim 180 \mathrm{~m} / \mathrm{s})$ to relatively higher $V_{\mathrm{S}}$ $(250-300 \mathrm{~m} / \mathrm{s})$ at the Pleistocene surface occurs at 14 and $\sim 18 \mathrm{~m}$ depth in the two SCPTs at the location. The transition is present in the tomograms at a depth varying between 12 and $25 \mathrm{~m}$, showing that the stratigraphy is variable even over distances as short as a couple of metres. Comparing the $V_{\mathrm{P}}$ and $V_{\mathrm{S}}$ tomograms shows that the $V_{\mathrm{S}} / V_{\mathrm{P}}$ or Poisson ratio is also highly variable over short distances and varies with depth.
2.5 Seismic interferometry at vertical seismic arrays

In addition to the determination of detailed $V_{\mathrm{S}}$ profiles at the surface recording stations, interval $V_{\mathrm{S}}$ have been derived at $\sim 70$ near-surface vertical seismic arrays that cover the Groningen region (Fig. 1). The seismic arrays consist of geophones at 200,150,100 and $50 \mathrm{~m}$ depth and an accelerometer at the surface. Local events are recorded over this near-surface borehole network. Shear-wave velocities at depth levels where seismicity occurs are an order of 10 times larger than near the surface. Consequently, shear waves bend towards vertical propagation in the near surface and are largely recorded on the horizontal components. This illumination is suitable to estimate seismic interval velocities between the receiver levels in the boreholes. Two methods were considered to determine the interval velocities. The first method uses the time differences of single phases after correction for the angle of incidence. These single phases exhibit large uncertainties, both on the timing and on the angle of incidence. The second method, which is applied here, is seismic interferometry on a catalogue of local events with sufficient signal-to-noise ratio (Hofman et al., 2017). Horizontal-component seismograms are rotated towards the transverse component and cross-correlated over different depth levels of single boreholes. By cross-correlating entire waveforms and stacking in cross-correlations of many different events, a precise estimate is obtained of the local seismic response: the waveforms are obtained as if there were a seismic source at one of the receiver levels and all the other receivers measured its response. The obtained response is dominated by a direct up-going and downgoing wave. From these waves, the timing is picked and converted to interval velocities along the boreholes. 
Fig. 11 Comparison of dispersion plots for station BKAN. Top: $4.5 \mathrm{~Hz}$ array of all 96 geophones. Middle: $4.5 \mathrm{~Hz}$ array of 12 geophones at corresponding locations of $1 \mathrm{~Hz}$ array. Bottom: $1 \mathrm{~Hz}$ array of 12 geophones
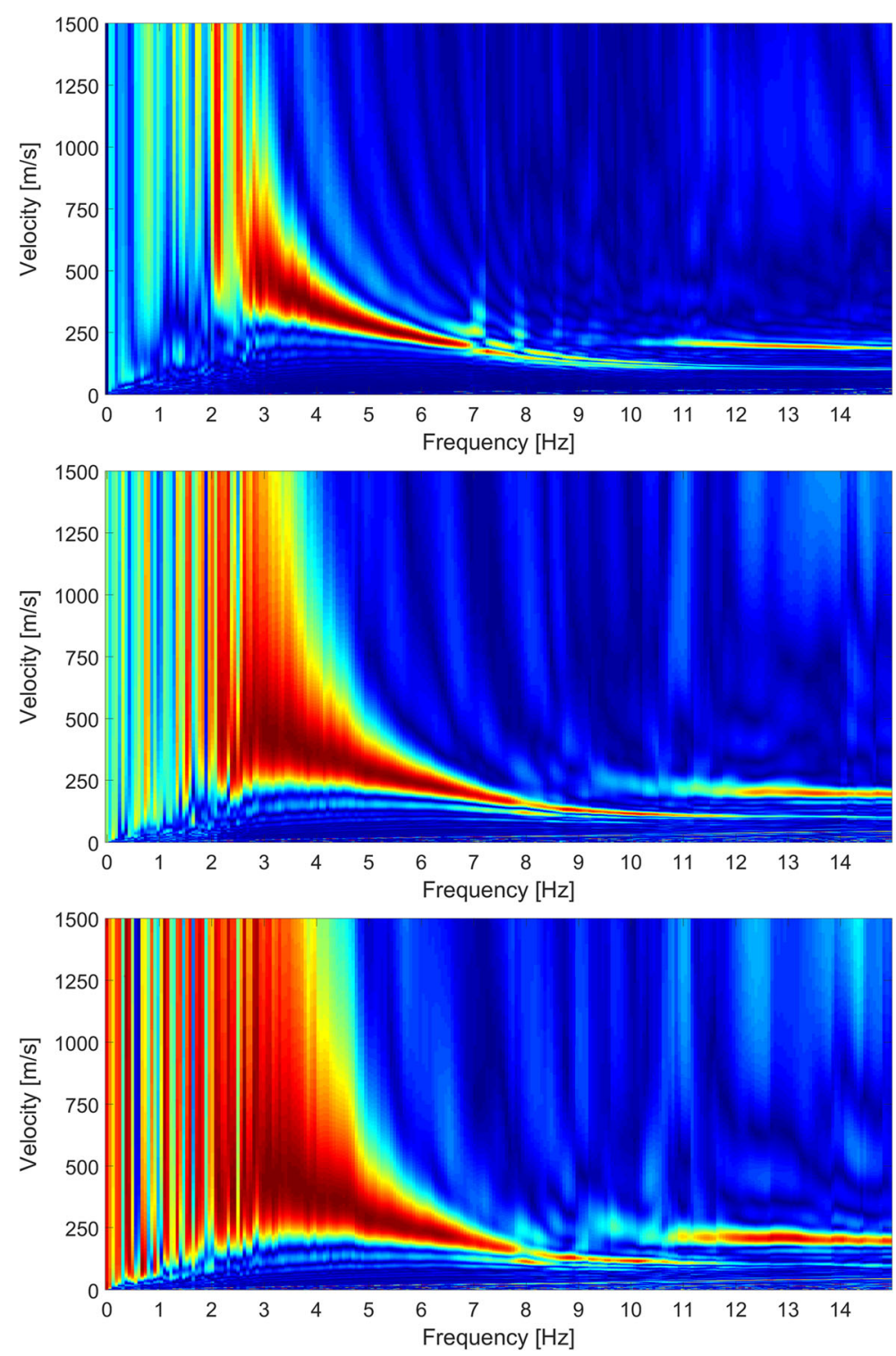

\section{Integration of various methods}

The various methods are based on different properties and behaviour of seismic waves and sample different kinds of soil volumes. All the results for one location are gathered and compared in Fig. 13. The sample volume of the methods and thus level of detail decreases from left to right. The SCPTs result in very detailed $V_{\mathrm{S}}$ profiles. However, they represent local $V_{\mathrm{S}}$ variations. The two SCPTs with $80 \mathrm{~m}$ offset near station BWSE are similar, but individual layers occur at slightly different depths and with varying $V_{\mathrm{S}}$ values. The $V_{\mathrm{S}}$ is low ( $130-140 \mathrm{~m} / \mathrm{s}$ ) between the surface and $\sim 8-9 \mathrm{~m}$ depth, next there is a faster layer of $\sim 2 \mathrm{~m}(225-460 \mathrm{~m} / \mathrm{s})$ below which there is an increase in $V_{\mathrm{S}}$ from $\sim 170 \mathrm{~m} / \mathrm{s}$ to $350 \mathrm{~m} / \mathrm{s}$ apart from a local high $V_{\mathrm{S}}$ layer at $18 \mathrm{~m}$ depth in SCPT04.

The original tomographic images of OSCPT and cross-hole $V_{\mathrm{S}}$ show the local variations in $V_{\mathrm{S}}$. In order to compare them to the other 1D profiles, they have been simplified by averaging $V_{\mathrm{S}}$ over depth slices. The $2 \mathrm{D}$ details, which are advantages of these methods, are lost in this way. The 1D OSCPT and 1D cross-hole profiles generally follow the SCPT profiles, but with less detail. The CMPcc and the MASW profile show a shallow $V_{\mathrm{S}}$ layer of $\sim 90 \mathrm{~m} / \mathrm{s}$ of $2 \mathrm{~m}$ at the top, followed by a $4 \mathrm{~m}$ 

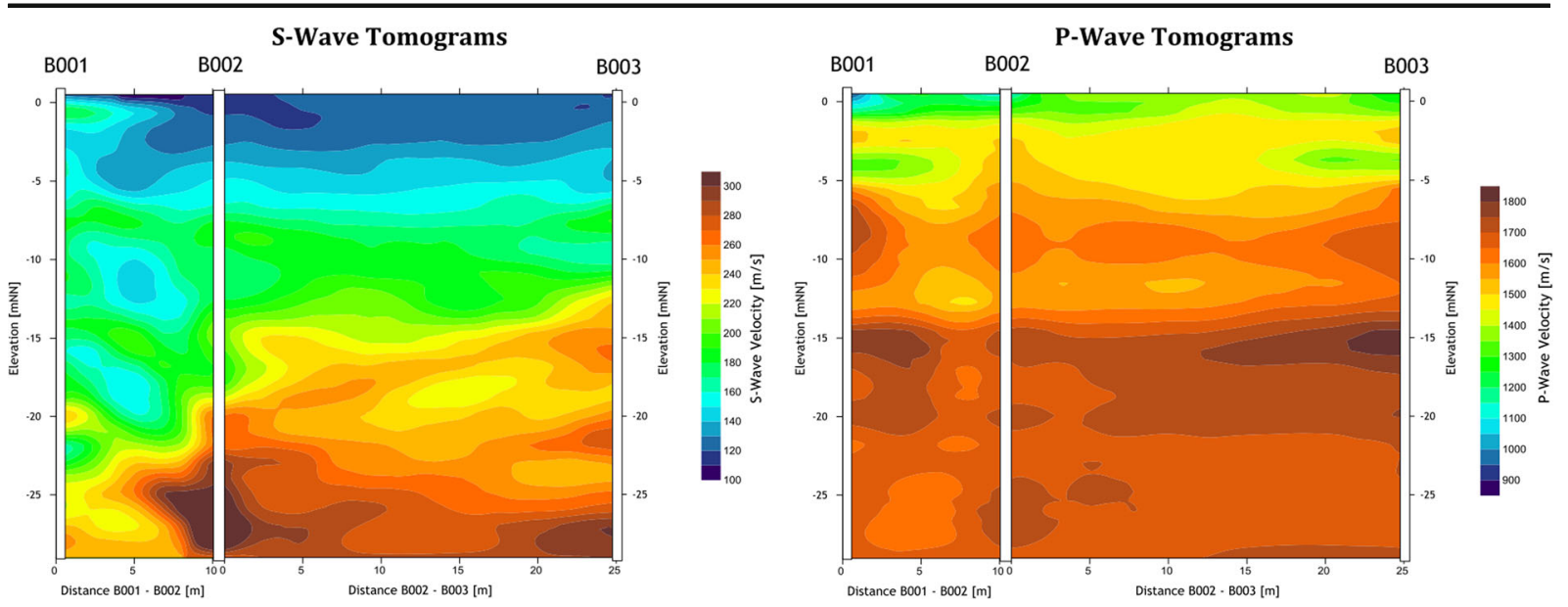

Fig. $12 V_{\mathrm{S}}$ and $V_{\mathrm{P}}$ images from cross-hole tomography for station BUHZ

thick layer of $\sim 150 \mathrm{~m} / \mathrm{s}$, a $9 \mathrm{~m}$ thick layer of $\sim 210 \mathrm{~m} / \mathrm{s}$ and a $4 \mathrm{~m}$ thick layer of $\sim 160 \mathrm{~m} / \mathrm{s}$. The very low $V_{\mathrm{S}}$ top layer in the MASW $V_{\mathrm{S}}$ profile is missed in the SCPT. Shear wave velocity results from the top $2-3 \mathrm{~m}$ in the SCPT cannot always be reliably determined due to the noisy record and the short distance of the waves travelled. This results in overlapping $\mathrm{P}$ and $\mathrm{S}$ waves in the record and the difficulty in reliably picking the $\mathrm{S}$ arrival. The gradual increase in $V_{\mathrm{S}}$ below $\sim 11 \mathrm{~m}$ that is apparent in the SCPT was not resolved in the MASW $V_{S}$ profile. The most representative $V_{\mathrm{S}}$ profile is a combination of the SCPT, cross-hole and the MASW $V_{\mathrm{S}}$ profiles with some weighing. For the present study, we adopted a pragmatic choice: the SCPT was combined with the top layer of MASW only if the SCPT results were unreliable for the top few metres. When two SCPTs were available, the station representative SCPT was chosen based on the distance between the SCPT and the station, the geology at the site and quality of the SCPT. To check the validity of the choice of SCPT, the theoretical dispersion curves of the SCPT were plotted on top of the MASW dispersion plot (Fig. 14). Because of the aforementioned possible unreliability of the top metres of the $V_{\mathrm{S}}$ from SCPT, the minimum $V_{\mathrm{S}}$ value of the top three layers was assumed for these layers. Generally, the fit is very good.

The 18 stations sample a variety of geological settings, but most stations are situated in areas with a Holocene cover on top of Pleistocene sediments. The average $V_{\mathrm{S}}$ is linked to the age of the deposits (Holocene or Pleistocene) and the lithology (peat, clay, sand). The transition between Holocene deposits (relatively low $V_{\mathrm{S}}$ ) and Pleistocene deposits (relatively high $V_{\mathrm{S}}$ ) is often easily recognised in the profiles by a jump from low $V_{\mathrm{S}}$ in the shallow layers to higher $V_{\mathrm{S}}$ values in the deeper layers (Fig. 15). This occurs at $11 \mathrm{~m}$ depth for station BMD2, at $9 \mathrm{~m}$ for BWIR, at $8 \mathrm{~m}$ at BAPP and at $9.5 \mathrm{~m}$ for BLOP. Individual peat layers can be recognised from their low $V_{\mathrm{S}}$, e.g. between 4.5 and $7 \mathrm{~m}$ at station BAPP. Between stations, the variation in $V_{\mathrm{S}}$ of the stratigraphic and lithological units is consistent. The general ranges of $V_{\mathrm{S}}$ for the Groningen deposits are $<100 \mathrm{~m} / \mathrm{s}$ for Holocene peat, $100-200 \mathrm{~m} / \mathrm{s}$ for Holocene clay and Pleistocene peat, $200-250 \mathrm{~m} / \mathrm{s}$ for Pleistocene clay and fine sand and $>250 \mathrm{~m} / \mathrm{s}$ for Pleistocene medium and coarse sand.

\section{Discussion}

4.1 Performance of techniques and sampling scales

The various techniques to determine $V_{\mathrm{S}}$ in the field generally perform well in the Groningen setting. The depth of penetration of SCPT is in most cases possible to the target depth of $30 \mathrm{~m}$. In some cases, this maximum was not achieved because of a combination of high friction due to stiff clay, high tip resistance or high friction in the Pleistocene sands. The MASW suffered from limited depth of penetration in some cases as well. The most apparent case is station BAPP where the top 7 to $8 \mathrm{~m}$ consists of very low $V_{\mathrm{S}}(<100 \mathrm{~m} / \mathrm{s})$ material. In this location, the dispersion could be determined down to approximately $1 \mathrm{~Hz}$, but the modelling shows that it only contains information from the top $15 \mathrm{~m}$. 

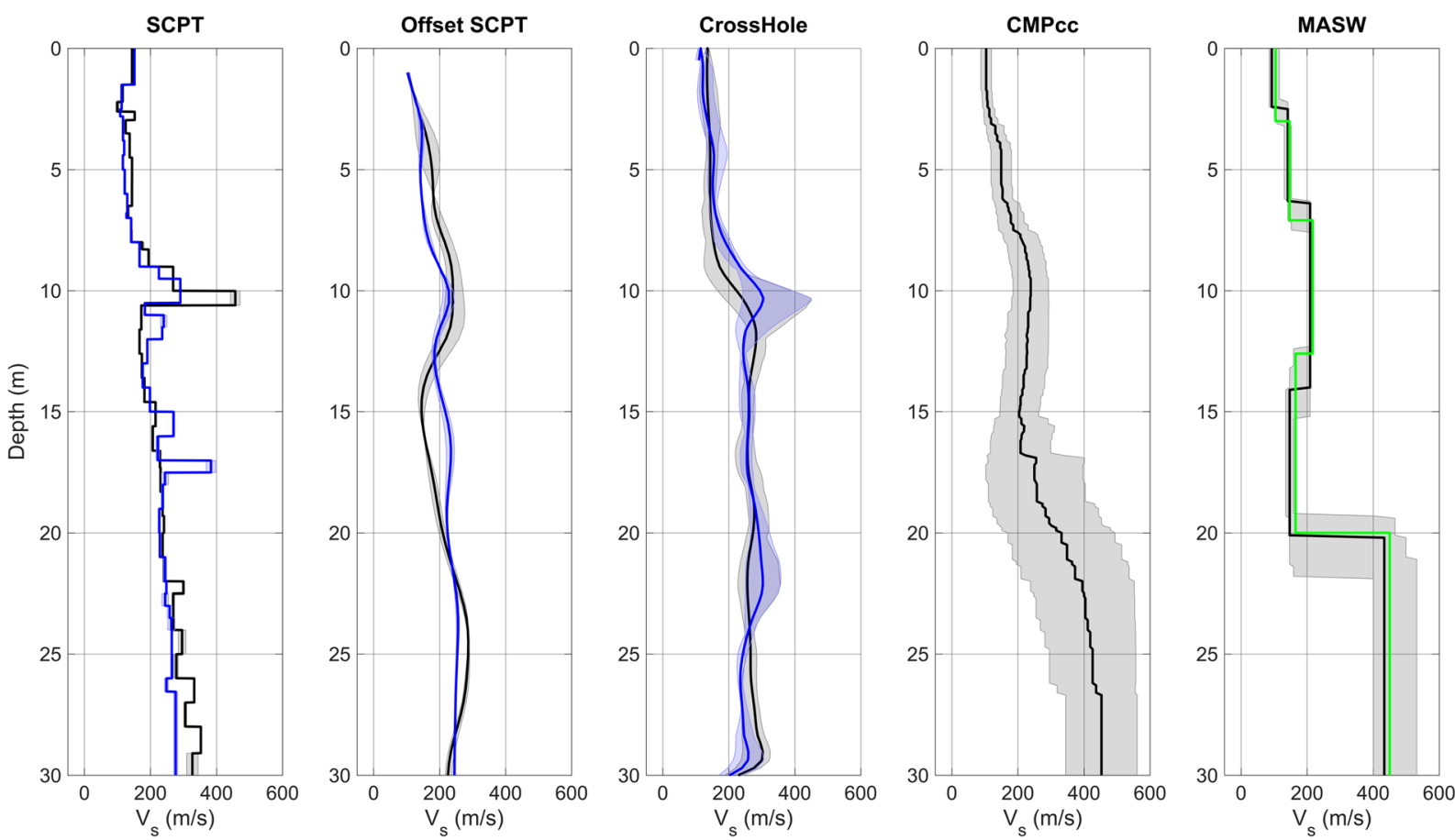

Fig. $13 V_{\mathrm{S}}$ profiles for station BWSE from different measurement techniques, including uncertainty bands. From left to right: SCPT03 (grey) and SCPT04 (blue) with band indicating variation between left and right blow; average profile for offset SCPTs between 1 and $5 \mathrm{~m}$ offset with shaded band indicating the minimum and the maximum $V_{\mathrm{S}}$; cross-hole average profiles for long leg (blue) and short leg (grey) with shaded band indicating the minimum and the maximum $V_{\mathrm{S}}$; CMPcc based on MASW array, shaded band indicates standard deviation of the 72 best models; MASW with manual fit in green and automatic inversion using the genetic algorithm in black with grey shaded band indicating the minimum and the maximum $V_{\mathrm{S}}$.
The SCPT and cross-hole techniques are based on picking shear-wave arrivals. The source-receiver distance needs to be sufficiently large to be able to reliably distinguish between the arrivals of different waves. For the cross-hole setup, the distance between source and receiver was always sufficiently large for reliable first arrival picking. For the SCPT, on the other hand, the distance between the source and receiver varies with depth, because the source stays at the surface while the receiver penetrates the soil. As a consequence, the quality of the data from the SCPT varies with depth: the top part might be unreliable when wave forms overlap. The unreliable top part (2-3 m) of the SCPT $V_{\mathrm{S}}$ profile was replaced by the more reliable MASW results for three of the 18 stations.
Fig. 14 Example of SCPT profile on MASW for station BWSE. Left: SCPT03 $V_{\text {S }}$ profile with the top 3 layers replaced by the minimum value. Right: theoretical dispersion curves of the $V_{\mathrm{S}}$ profile for fundamental (green) and higher modes (red, blue, cyan and yellow) plotted on top of the MASW dispersion plot (grey scale) for station BWSE
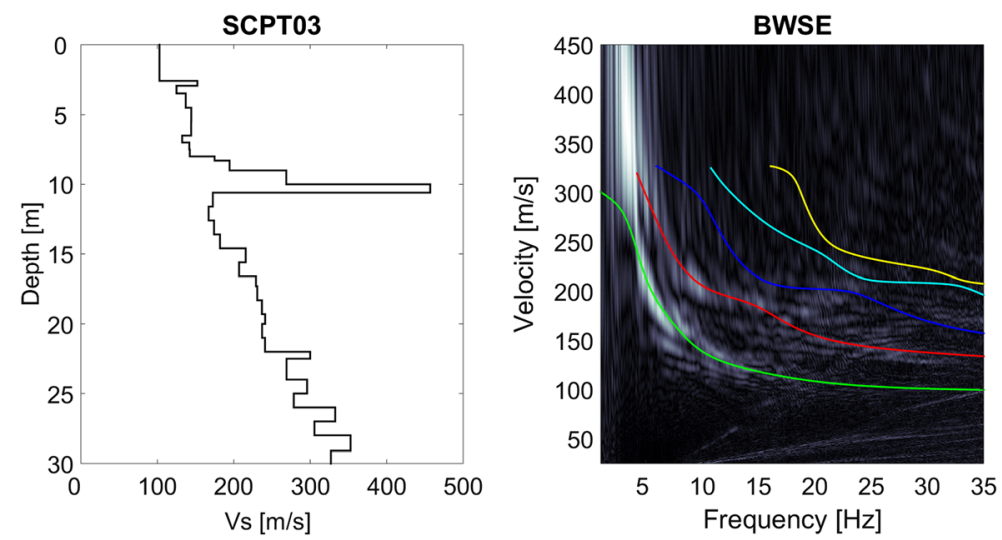
Fig. $15 V_{\mathrm{S}}$ profiles at selected B stations. Measured $V_{\mathrm{S}}$ in blue and modelled mean $V_{\mathrm{S}}$ (Kruiver et al., 2017a) in red

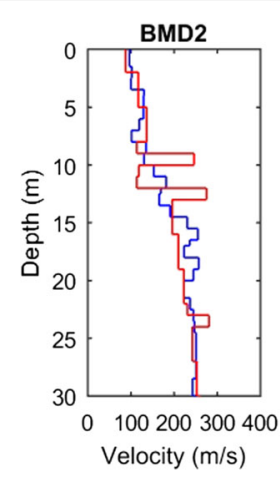

BWIR

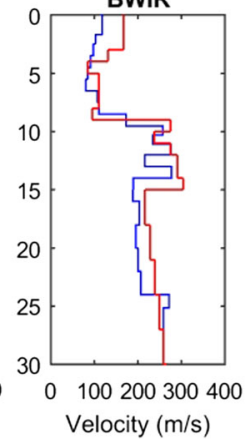

BAPP

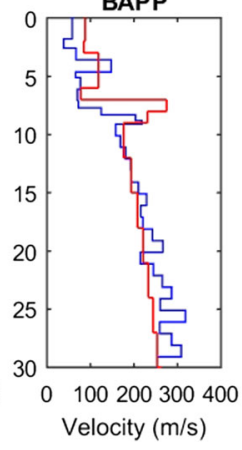

BLOP

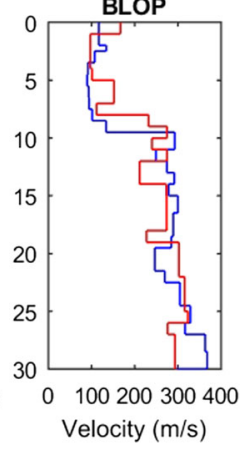

We demonstrated that the resolution and scale at which the different methods obtain the $V_{\mathrm{S}}$ profile is quite different. The surface-wave method 'averages' the $V_{\mathrm{S}}$ information over the whole array length of approximately $200 \mathrm{~m}$ and therefore is only sensing $V_{\mathrm{S}}$ structures if they have a significant contrast, thickness and lateral extent. On the other hand, the SCPT method samples the velocity on a scale of a few metres at most. The OSCPT and cross-hole methods sample the data at intermediate scale. It is clear from the OSCPT, cross-hole and CMPcc results and the locations with two SCPT profiles that changes in velocities can be significant over small distances. Therefore, it is important to consider the relation between the scale of the $V_{\mathrm{S}}$ profile from a certain method and scale at which earthquake amplification occurs. The primary goal of the $V_{\mathrm{S}}$ measurements was to calibrate the transfer functions. A pragmatic choice was made to use the SCPT close to the accelerometer station (with MASW for the uppermost few metres when needed) for calculation, because it is both most detailed and contains extra information on lithology and shallow stratigraphy.

\subsection{Comparison to other types of $V_{\mathrm{S}}$ estimates} and derived analyses

Additional to providing $V_{\mathrm{S}}$ profiles for the ground motion model, the SCPT $V_{\mathrm{S}}$ values were used to derive a $V_{\mathrm{S}}$ model for Groningen. For this, SCPT $V_{\mathrm{S}}$ from this fieldwork and from archive data were classified in terms of stratigraphy and lithology to derive $V_{\mathrm{S}}$ distributions (Kruiver et al. 2017a). These $V_{S}$ distributions were used to model $V_{\mathrm{S}}$ in the entire Groningen field in the top $50 \mathrm{~m}$ using the detailed 3D voxel model of geology GeoTOP of TNO Geological Survey of the Netherlands (Stafleu et al., 2011; Maljers et al., 2015; Stafleu and Dubelaar, 2016). The modelled $V_{\mathrm{S}}$ profiles at the stations are shown in Fig. 15 for comparison with the in situ measured $V_{\mathrm{S}}$. There is generally good agreement between the measured $V_{\mathrm{S}}$ at the site and the modelled values, especially considering the regional character of the GeoTOP model.

Theoretical 1D SH-wave site transfer functions (TFs) were calculated for each of the measured $V_{\mathrm{S}}$ profiles at the $\mathrm{B}$ stations. These transfer functions were used to deconvolve Fourier amplitude spectra (FAS) of surface recordings to a reference horizon, at some $800 \mathrm{~m}$ depth, for the purpose of determining seismological parameters for modelling earthquake ground motions (Bommer et al., 2017). The simulated ground motions were then used in a non-linear soil response analysis using a fieldwide velocity model (Kruiver et al., 2017a) to determine zone-specific spectral acceleration amplification functions (AFs) for use in hazard and risk analyses (Rodriguez-Marek et al., 2017). As such, it is important to verify both the consistency of the $V_{\mathrm{S}}$ models and the accuracy and applicability of the site TFs. At the Gstations from the KNMI monitoring network, no in situ measured $V_{\mathrm{S}}$ data are available. The $V_{\mathrm{S}}$ profiles inferred from seismic interferometry at selected G-stations and the modelled $V_{\mathrm{S}}$ profiles are compared in Fig. 16. The modelled $V_{\mathrm{S}}$ data have been converted to interval velocities corresponding to the geophone intervals by determination of the harmonic means. These compare very well to the interval velocities estimated from seismic interferometry. The main uncertainty in the velocities estimated with seismic interferometry is related to interference between the direct waves and the reflected phases and noise. In Hofman et al. (2017), confidence ranges are added to all estimated profiles. For $V_{\mathrm{S}}$, the confidence regions are generally very small and only exceed $20 \mathrm{~m} / \mathrm{s}$ for a limited number of very noisy stations. Differences in the estimated and modelled $V_{\mathrm{S}}$ in the top $50 \mathrm{~m}$ can be attributed to local variations in geology at the station sites relative to the GeoTOP model. 

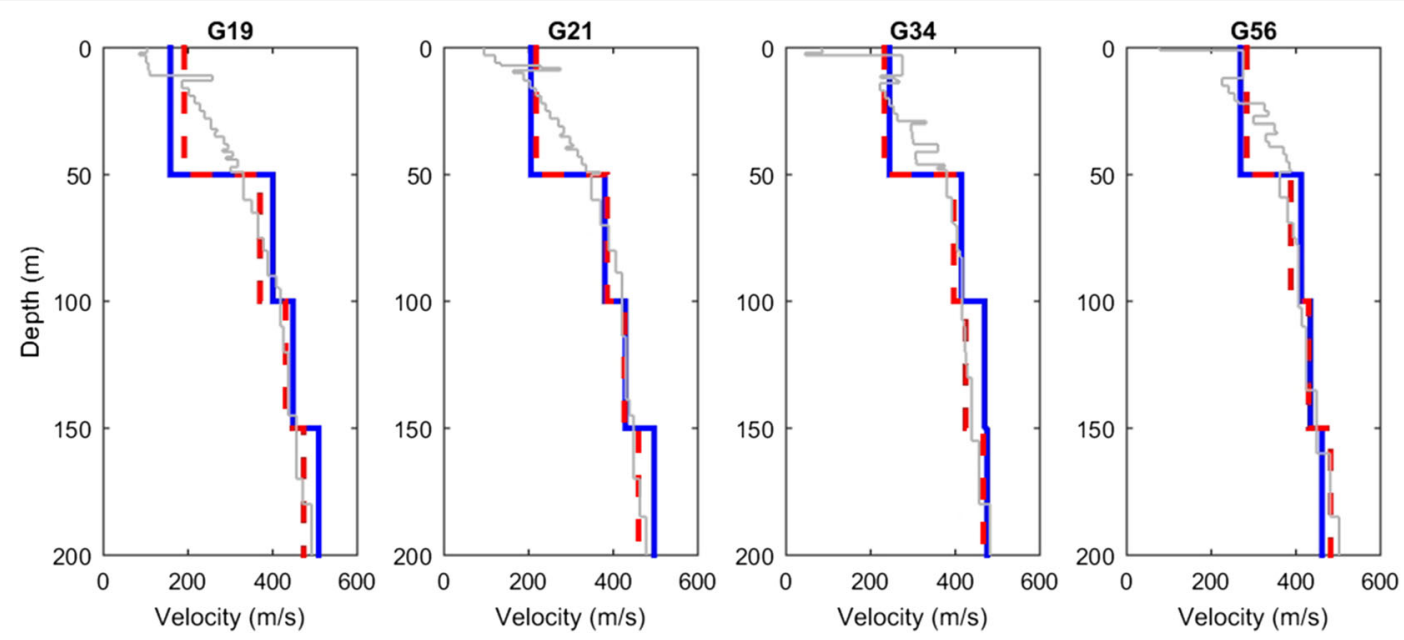

Fig. $16 V_{\mathrm{S}}$ profiles at selected $\mathrm{G}$ stations. Interval $V_{\mathrm{S}}$ from seismic interferometry in blue, modelled mean $V_{\mathrm{S}}$ (Kruiver et al., $\left.2017 \mathrm{a}\right)$ in grey and harmonic means of modelled $V_{\mathrm{S}}$ in dashed red

Independent calculation of site transfer functions is typically performed using site-to-reference spectral ratios, or in the absence of a reference site (as in Groningen), by calculating empirical transfer functions from spectral modelling (Edwards et al., 2013). This approach has been successfully used in guiding the development of $V_{\mathrm{S}}$ models in Alpine and urban regions of Switzerland (Michel et al., 2014, 2016). The principal of empirical transfer functions is to isolate site effects. The approach of Edwards et al. (2013) uses a simple seismological pointsource model (Brune, 1970; Anderson and Hough, 1984) to account for source and path effects in recordings of small earthquakes. Consistent site effects are then extracted from the intra-event FAS residuals over numerous events. By averaging over numerous events, distances and azimuths and extracting only the intra-event residuals, the non-uniqueness of spectral analysis approaches is largely removed (Goertz-Allmann and Edwards, 2013; Michel et al., 2014, 2016). The result is that site TFs are - over a broad frequency band-independent from the inverted source and path effects. Furthermore, in this analysis, we take advantage of the availability of the measured $V_{\mathrm{S}}$ as a priori information for the inversions and reduce possible trade-offs further. The 1D SH TF with vertical incidence from measured $V_{\mathrm{S}}$ profile is used as a starting model, with the inversion completely free to modify the TFs.

Figure 17 shows a comparison of the TFs for four sites with measured $V_{\mathrm{S}}$ profiles. The overall shape of the empirical TFs (determined from earthquake recordings
Fig. 17 Comparison for selected B stations of empirical amplification (reservoir to surface amplification) from the Groningen earthquake recordings database (blue) and standard deviation (pale blue) along with the theoretical vertical 1D SH amplification between the reference and surface (red) based on numerical linear site response analyses
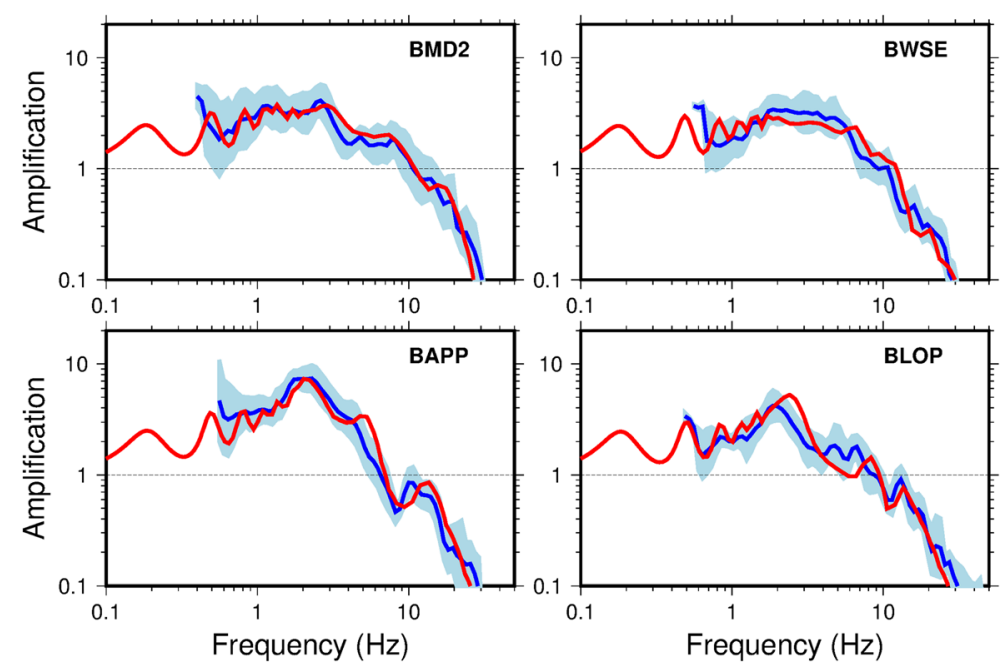
Fig. 18 Comparison for selected $\mathrm{G}$ stations of FAS spectral ratio of surface to $200 \mathrm{~m}$ depth from the Groningen earthquake recordings database (blue) and standard deviation (pale blue) along with the spectral ratio of surface to $200 \mathrm{~m}$ depth from theoretical 1D SH linear site response analyses (solid red). The dashed red line indicates the 1D SH TF at the surface and dotted red line at $200 \mathrm{~m}$ depth
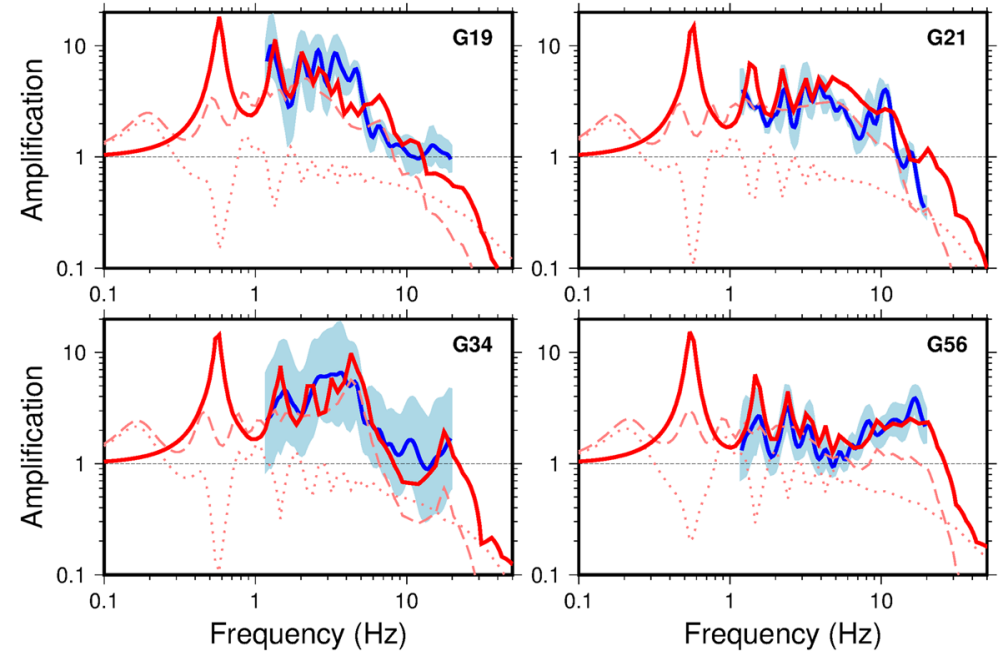

following Edwards et al., 2013) and theoretical 1D SH TFs (determined from numerical linear site response analysis) is very similar, with only small differences in minor peaks and troughs. For the borehole $(\mathrm{G})$ stations there are no measured $V_{\mathrm{S}}$ profiles. However, in this case, we can take advantage of the surface-to-borehole-at200 m-depth (S/B) spectral ratio to calculate the effect of the soil column on the wavefield. Figure 18 shows S/B spectral ratios calculated using small earthquakes (1.5> $\mathrm{M}_{\mathrm{L}}$ > 3.1). In order to compare $\mathrm{S} / \mathrm{B}$ spectral ratios with theoretical transfer functions, the TF between the borehole at $200 \mathrm{~m}$ depth (within-rock: i.e. accounting for both up- and down-going waves) and the outcropping surface must be calculated. This is equivalent to taking the ratio of the TFs between the reference horizon and both the outcropping surface and the $200 \mathrm{~m}$ depth 'within-rock' borehole levels. Generally, the amplification from the recordings and theoretical transfer functions agree well.

The good agreement between measured/inferred $V_{\mathrm{S}}$ and modelled $V_{\mathrm{S}}$ from Fig. 17 and Fig. 18 indicates that the use of vertical 1D SH TFs is appropriate over the $800 \mathrm{~m}$ from reference rock horizon to surface. The velocity models determined for the reference to surface produce remarkably similar TFs to those empirically observed in earthquake signals.

\section{Conclusions}

A fieldwork campaign was conducted in the Groningen gas field to determine in situ $V_{\mathrm{S}}$ to approximately $30 \mathrm{~m}$ depth for the purpose of reducing uncertainty in the ground motion model for induced earthquakes. A suite of field techniques was used and existing techniques were extended. For example, the SCPT procedure was adjusted to take measurements at stratigraphy boundaries in order to sample each layer (especially peat) in sufficient detail and to avoid contamination of the measured $V_{\mathrm{S}}$ by the under- or overlying soil layer. We added source offsets to the SCPT (OSCPT) at 1 to $20 \mathrm{~m}$ from the cone location to be able to perform tomography of $V_{\mathrm{S}}$. This provided insights regarding spatial variations of $V_{\mathrm{S}}$ and representativeness of any individual SCPT.

The cross-hole tomography also showed that there is heterogeneity on spatial scales of one to several metres. For example, the jump in $V_{\mathrm{S}}$ associated with the transition between Holocene and Pleistocene deposits varies in depth by several metres over a horizontal distance of $25 \mathrm{~m}$. The cross-hole tomography is very suitable to investigate spatial variation of $V_{\mathrm{P}}$ and $V_{\mathrm{S}}$ properties.

The MASW analysis consisted of both active and ambient noise data acquisition and various methods of processing. The classic MASW processing of the offset gather of the array resulted in the large scale $V_{\mathrm{S}}$ structures at the station sites. The passive and the MASW dispersion characteristics matched well. However, the microtremor array data did not significantly extend the bandwidth of the dispersion data relative to the MASW at our sites. This could be improved by including lower frequency geophones and ambient noise data collection for a longer period of time. The CMPcc approach on the MASW data indicated the lateral variability of $V_{\mathrm{S}}$ along the full array. 
We made a pragmatic choice to achieve the final $V_{\mathrm{S}}$ profile at each station, using the SCPT, only substituting by the MASW value when the SCPT was unreliable. The comparison between the measured $V_{\mathrm{S}}$ and the modelled $V_{\mathrm{S}}$ that was used for site response analysis shows an excellent match. The correspondence between the $V_{\mathrm{S}}$ from seismic interferometry and the modelled $V_{\mathrm{S}}$ agrees very well. The measured $V_{\mathrm{S}}$ profiles significantly enhanced the ground motion model derivation by using them to deconvolve the recorded motions from the Groningen earthquake database to the reference baserock horizon.

Acknowledgements A large team of geophysicists and assistants made this fieldwork campaign possible. The access to the station locations was negotiated by Janny Teunissen, Eddie Siemerink and Willem Hermse (NAM) and Bernard Dost (KNMI). We wish to thank the following people for their assistance in the field: Rogier Westerhoff, Victor Hopman, Mike van der Werf, Veronique Marges, Pieter Doornenbal (Deltares, the Netherlands) and Miel Kuhr and Maarten Malingré. Suspension P-S logging was performed by Graham Comber (Robertson Geologging, UK). Thomas Fechner (Geotomographie GmbH, Germany) assisted in the cross-hole tomography. Kees-Jan van der Made, Jan Dijkstra and Rolf Reker (Wiertsema \& Partners, the Netherlands) performed the SCPTs under supervision of Deltares. We are grateful to the Associate Editor and to one anonymous reviewer for constructive critical feedback on an earlier version of this paper.

Open Access This article is distributed under the terms of the Creative Commons Attribution 4.0 International License (http:// creativecommons.org/licenses/by/4.0/), which permits unrestricted use, distribution, and reproduction in any medium, provided you give appropriate credit to the original author(s) and the source, provide a link to the Creative Commons license, and indicate if changes were made.

\section{References}

Aki K (1957) Space and time spectra of stationary stochastic waves, with special reference to microtremors. Bull Earthq Inst Univ Tokyo 35:415-457

Anderson JG, Hough SE (1984) A model for the shape of the Fourier amplitude spectrum of acceleration at high-frequencies. Bull Seismol Soc Am 74:1969-1993

Bommer JJ, Stafford PJ, Edwards B, Dost B, van Dedem E, Rodriguez-Marek A, Kruiver PP, van Elk J, Doornhof D (2017) Framework for a ground-motion model for induced seismic hazard and risk analysis in the Groningen gas field. Earthquake Spectra 33(2):481-498. https://doi.org/10.1193 /082916EQS138M

Brune JN (1970) Tectonic stress and spectra of seismic shear waves from earthquakes. J Geophys Res 75(26):49975009. https://doi.org/10.1029/JB075i026p04997
Butcher, A. P., Campanella, R.G., Kaynia, A.M., Massarsch, K. R. (2005) Seismic cone downhole procedure to measure shear wave velocity - a guideline. Report of Tech. Com. TC10, Geophysical Testing, Int. Soc. Soil Mech. \& Geotech. Eng., ISSMGE 5

Edwards B, Michel C, Poggi V, Fäh D (2013) Determination of site amplification from regional seismicity: application to the Swiss National Seismic Networks. Seismol Res Lett 84(4): 611-621. https://doi.org/10.1785/0220120176

Garofalo F, Foti S, Hollender F, Bard PY, Cornou C, Cox BR, Ohrnberger M, Sicilia D, Asten M, Di Giulio G, Forbiger T, Guillier B, Hayashi K, Martin A, Matsushima S, Mercerat D, Poggi V, Yamanaka H (2016a) InterPACIFIC project: comparison of invasive and non-invasive methods for seismic site characterization. Part I: intra-comparison of surface wave methods. Soil Dyn Earthq Eng 82:222-240. https://doi. org/10.1016/j.soildyn.2015.12.010

Garofalo F, Foti S, Hollender F, Bard PY, Cornou C, Cox BR, Dechamp A, Ohrnberger M, Perron V, Sicilia D, Teague D, Verniault C (2016b) InterPACIFIC project: comparison of invasive and non-invasive methods for seismic site characterization. Part II: inter-comparison between surface-wave and borehole methods. Soil Dyn Earthq Eng 82:241-254. https://doi.org/10.1016/j.soildyn.2015.12.009

Gilbert P (1972) Iterative methods for the three dimensional reconstruction of an object from projections. J Theor Biol 36(1):105-117. https://doi.org/10.1016/0022-5193(72 )90180-4

Goertz-Allmann BP, Edwards B (2013) Constraints on crustal attenuation and three-dimensional spatial distribution of stress drop in Switzerland. Geophys J Int 196(1):493-509. https://doi.org/10.1093/gji/ggt384

Hayashi K, Suzuki H (2004) CMP cross-correlation analysis of multi-channel surface-wave data. Explor Geophys 35(1):713. https://doi.org/10.1071/EG04007

Hofman, LJ, Ruigrok E, Dost B, Paulssen H (2017) A shallow velocity model for the Groningen area in the Netherlands, J Geophys Res Solid Earth 122:8035-8050. https://doi. org/10.1002/2017JB014419

Kruiver PP, van Dedem E, Romijn R, de Lange G, Korff M, Stafleu J, Rodriguez-Marek A, van Elk J, Doornhof D (2017a) An integrated shear-wave velocity model for the Groningen gas field. Bull Earthq Eng 15(9):3555-3580. https://doi.org/10.1007/s10518-017-0105-y

Kruiver PP, Wiersema A, Kloosteman FH, de Lange G, Korff M, Stafleu J, Busschers FS, Harting R, Gunnink JL, van Elk J, Doornhof D (2017b) Characterisation of the Groningen subsurface for seismic hazard and risk modelling. Accepted for publication in Netherlands Journal of Geosciences

Maljers D, Stafleu J, van der Meulen MJ, Dambrink RM (2015) Advances in constructing regional geological voxel models, illustrated by their application in aggregate resource assessments. Neth J Geosci 94:257-270

Michel C, Edwards B, Poggi V, Burjanek J, Roten D, Cauzzi C, Fäh D (2014) Assessment of site effects in alpine regions through systematic site characterization of seismic stations. Bull Seismol Soc Am 104(6):2809-2826. https://doi. org/10.1785/0120140097

Michel C, Fäh D, Edwards B, Cauzzi C (2016) Site amplification at the city scale in Basel (Switzerland) from geophysical site characterization and spectral modelling of recorded 
earthquakes. Phys Chem Earth, Parts A/B/C 98:27-40. https://doi.org/10.1016/j.pce.2016.07.005

Mulargia F, Castellaro S (2013) A seismic passive imaging step beyond SPAC and ReMi. Geophysics 78(5):KS63-KS72. https://doi.org/10.1190/geo2012-0405.1

Ogura K, Uchiyama S, Ohhashi T, Saito H (1989) Study of continuous measurement of suspension P-S logging. SEG Technical Program Expanded Abstracts 1989:43-46. https://doi.org/10.1190/1.1889692

Ohori M, Nobata A, Wakamatsu K (2002) A comparison of ESAC and FK methods of estimating phase velocity using arbitrarily shaped microtremor arrays. Bull Seismol Soc Am 92(6): 2323-2332. https://doi.org/10.1785/0119980109

Ohya S, Ogura K, Imai T (1984) The suspension PS velocity logging system. Offshore Technol Conf. https://doi. org/10.4043/4680-MS

Okada H (2003) The microtremor survey method, Geophysical Monograph Series Number 12: Tulsa, Oklahoma, Society of Exploration Geophysicists, $135 \mathrm{p}$

Park CB, Miller RD, Xia J (1999) Multichannel analysis of surface waves. Geophysics 64 (3):800-808. https://doi.org/10.1190 $/ 1.1444590$
Rodriguez-Marek A, Kruiver PP, Meijers P, Bommer JJ, Dost B, van Elk J, Doornhof D (2017) A regional site-response model for the Groningen gas field. Bull Seismol Soc Am 108(5): 2067-2077. https://doi.org/10.1785/0120160123.

Sethian JA (1999) Fast marching methods. SIAM Rev 41(2):199_ 235. https://doi.org/10.1137/S0036144598347059

Stafleu J, Maljers D, Gunnink JL, Menkovic A, Busschers FS (2011) 3D modeling of the shallow subsurface of Zeeland, the Netherlands. Neth J Geosci 90:293-310

Stafleu J, Dubelaar CW (2016) Product specification subsurface model GeoTOP. TNO Report 2016-R10133 v1.3, 53 pp. Available at: www.dinoloket.nl/en/want-know-more.

Watanabe T, Matsuoka T, Ashida Y (1999) Seismic traveltime tomography using Fresnel volume approach. SEG Tech Program Expanded Abstracts 18:1402-1405

Yong A, Martin A, Stokoe K, Diehl J (2013) ARRA-funded $V_{\text {S30 }}$ measurements using multi-technique approach at strongmotion stations in California and central-eastern United States (Open-File Report 2013-1102). US Geological Survey, $59 \mathrm{p}$ 